\title{
Mechanisms of cannabinoid $\mathrm{CB}_{2}$ receptor-mediated reduction of dopamine neuronal excitability in mouse ventral tegmental area
}

\author{
Zegang Ma ${ }^{\mathrm{a}, \mathrm{b}}$, Fenfei Gao ${ }^{\mathrm{c}, \mathrm{b}}$, Brett Larsen ${ }^{\mathrm{b}, \mathrm{d}}$, Ming Gao ${ }^{\mathrm{b}}$, Zhihua Luo ${ }^{\mathrm{c}}$, Dejie Chen ${ }^{\text {b,e }}$, Xiaokuang Ma ${ }^{\text {b,c,d }}$, \\ Shenfeng Qiu ${ }^{\mathrm{d}}$, Yu Zhou ${ }^{\mathrm{a}}$, Junxia Xie ${ }^{\mathrm{a}}$, Zheng-Xiong Xi ${ }^{\mathrm{f}}$, Jie Wu ${ }^{\mathrm{a}, \mathrm{b}, \mathrm{c}, \mathrm{e}, *}$
}

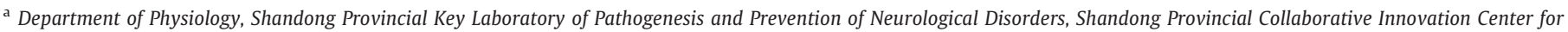
Neurodegenerative Disorders and State Key Disciplines: Physiology, Medical College of Qingdao University, Qingdao 266071, China

b Department of Neurobiology, St. Joseph's Hospital and Medical Center, Barrow Neurological Institute, Phoenix, AZ 85013, USA

c Department of Pharmacology, Shantou University Medical College, Shantou, Guangdong 210854, China

d Department of Basic Medical Sciences, University of Arizona College of Medicine, Phoenix, AZ 85004, USA

e Department of Neurology, Yunfu People's Hospital, Yunfu, Guangdong 527300, China

${ }^{\mathrm{f}}$ Molecular Targets and Medications Discovery Branch, Intramural Research Program, National Institute on Drug Abuse, Baltimore, MD 21224, USA

\section{A R T I C L E I N F O}

\section{Article history:}

Received 10 January 2019

Received in revised form 24 February 2019

Accepted 14 March 2019

Available online 3 April 2019

\section{Keywords:}

Cannabinoid

CB2 receptor

Ventral tegmental area

Dopamine neuron

\begin{abstract}
A B S T R A C T
Background: We have recently reported that activation of cannabinoid type 2 receptors $\left(\mathrm{CB}_{2} \mathrm{Rs}\right)$ reduces dopamine (DA) neuron excitability in mouse ventral tegmental area (VTA). Here, we elucidate the underlying mechanisms.

Methods: Patch-clamp recordings were performed in mouse VTA slices and dissociated single VTA DA neurons. Findings: Using cell-attached recording in VTA slices, bath-application of $\mathrm{CB}_{2} \mathrm{R}$ agonists (JWH133 or five other $\mathrm{CB}_{2} \mathrm{R}$ agonists) significantly reduced VTA DA neuron action potential (AP) firing rate. Under the patch-clamp whole-cell recording model, JWH133 $(10 \mu \mathrm{M})$ mildly reduced the frequency of miniature excitatory postsynaptic currents (mEPSCs) but not miniature inhibitory postsynaptic currents (mIPSCs). JWH133 also did not alter evoked EPSCs or IPSCs. In freshly dissociated VTA DA neurons, JWH133 reduced AP firing rate, delayed AP initiation and enhanced AP after-hyperpolarization. In voltage-clamp recordings, JWH133 (1 $\mu \mathrm{M})$ enhanced M-type $\mathrm{K}^{+}$currents and this effect was absent in $\mathrm{CB}_{2}^{-1-}$ mice and abolished by co-administration of a selective $\mathrm{CB}_{2} \mathrm{R}$ antagonist $(10 \mu \mathrm{M}, \mathrm{AM} 630)$. $\mathrm{CB}_{2} \mathrm{R}$-mediated inhibition in VTA DA neuron firing can be mimicked by M-current opener (10 $\mu \mathrm{M}$ retigabine) and blocked by M-current blocker (30 $\mu \mathrm{M}$ XE991). In addition, enhancement of neuronal cAMP by forskolin $(10 \mu \mathrm{M})$ reduced $\mathrm{M}$-current and increased DA neuron firing rate. Finally, pharmacological block of synaptic transmission by NBQX $(10 \mu \mathrm{M})$, D-APV $(50 \mu \mathrm{M})$ and picrotoxin $(100 \mu \mathrm{M})$ in VTA slices failed to prevent $\mathrm{CB}_{2} \mathrm{R}$-mediated inhibition, while intracellular infusion of guanosine 5'-0-2-thiodiphosphate ( $600 \mu \mathrm{M}$, GDP- $\beta-S$ ) through recording electrode to block postsynaptic G-protein function prevented JWH133-induced reduction in AP firing.

Interpretation: Our results suggest that $\mathrm{CB}_{2}$ Rs modulate VTA DA neuron excitability mainly through an intrinsic mechanism, including a $\mathrm{CB}_{2} \mathrm{R}$-mediated reduction of intracellular $\mathrm{CAMP}$, and in turn enhancement of M-type $\mathrm{K}^{+}$currents.

Fund: This research was supported by the Barrow Neuroscience Foundation, the BNI-BMS Seed Fund, and CNSF (81771437).

(C) 2019 The Authors. Published by Elsevier B.V. This is an open access article under the CC BY-NC-ND license (http:// creativecommons.org/licenses/by-nc-nd/4.0/).
\end{abstract}

\section{Introduction}

The $\mathrm{CB}_{2} \mathrm{R}$ is a $\mathrm{G}$-protein-coupled receptor that was cloned in 1993 [5]. Since then, the expression and function of $\mathrm{CB}_{2} \mathrm{Rs}$ in the brain has

\footnotetext{
* Corresponding author at: Divisions of Neurology and Neurobiology, St. Joseph's Hospital and Medical Center, Barrow Neurological Institute, 350 W Thomas Road, Phoenix, AZ, USA

E-mail address: Jie.Wu@DignityHealth.org (J. Wu).
}

been debated. Early studies suggested that $\mathrm{CB}_{2}$ Rs were absent in the brain because $\mathrm{CB}_{2}$ mRNA transcripts were not detected in brain tissues [1-4]. Based on these findings, the $\mathrm{CB}_{2} \mathrm{R}$ has been considered as a "peripheral" cannabinoid receptor [5-7]. Recently, this concept has been challenged by the identification of $\mathrm{CB}_{2} \mathrm{R}$ mRNA and receptor proteins throughout the central nervous system (CNS) [8,9], including the cerebral cortex [10], hippocampus [11], striatum [12], amygdala and brainstem [12-17]. Immunoblot and immunohistochemistry (IHC) assay also detect $\mathrm{CB}_{2} \mathrm{R}$-immunoreactivity or immunostaining in various 


\section{Research in context}

\section{Evidence before this study}

Cannabis sativa (marijuana) is a fibrous flowering plant that naturally produces an abundant variety of molecules, some with psychoactive effects. At least $4 \%$ of the world's adult population uses cannabis annually, making it one of the most frequently used illicit drugs in the world. The psychoactive effects of cannabis are mediated primarily through two cannabinoid receptor (CBR) subtypes, $C B_{1} R$ and $C_{2} R$. The prevailing view is that $\mathrm{CB}_{1}$ Rs are mainly expressed in central neurons while $\mathrm{CB}_{2} \mathrm{R}$ s are predominantly expressed in peripheral immune cells. However, this traditional view has been challenged by strong emerging evidence that shows $\mathrm{CB}_{2} \mathrm{Rs}$ are moderately expressed and function in specific brain areas. New evidence has demonstrated that brain $\mathrm{CB}_{2}$ Rs mediate important modulations in animal cocaineseeking behaviors (Xi et al., Nature of Neuroscience, Jul 24;14 [9]:1160-6, 2011), suggesting that these receptors may exist in the brain regions that regulate drug addiction. Recently, we further confirmed that functional $\mathrm{CB}_{2} \mathrm{Rs}$ are expressed in mouse ventral tegmental area (VTA) DA neurons, and activation of VTA CB ${ }_{2} R s$ reduces neuronal excitability and cocaine-seeking behavior (Zhang et al., PNAS 111 [46]:E5007-15, 2014). However, the mechanisms and the $\mathrm{CB}_{2} \mathrm{R}-\mathrm{G}$ protein intracellular signaling that underlies these VTA $\mathrm{CB}_{2} \mathrm{R}$-mediated modulations are unknown.

\section{Added value of this study}

In this paper, we elucidate the underlying mechanisms. Using cellattached recording in VTA slices, bath-application of a $\mathrm{CB}_{2} \mathrm{R}$ agonist (JWH133) inhibited VTA DA neuron firing in a concentrationdependent manner. In addition to JWH133, five other $\mathrm{CB}_{2} \mathrm{R}$ agonists exhibited similar inhibition. Under the patch-clamp wholecell recording model, JWH133 $(10 \mu \mathrm{M})$ inhibited miniature excitatory postsynaptic currents (mEPSCs) but not miniature inhibitory postsynaptic currents (mIPSCs). However, JWH133 did not inhibit evoked EPSCs or IPSCs. In freshly dissociated VTA DA neurons, JWH133 reduced the action potential (AP) firing rate, delayed AP initiation and enhanced AP after-hyperpolarization. In voltage-clamp recordings, $\mathrm{M}$-type $\mathrm{K}^{+}$currents were enhanced by JWH133. This effect was absent in $\mathrm{CB}_{2}^{-1-}$ mice and abolished by co-administration of a selective $\mathrm{CB}_{2} \mathrm{R}$ antagonist (AM630). In addition, $\mathrm{CB}_{2} \mathrm{R}$-mediated inhibition in VTA DA neuron firing can be mimicked by an $\mathrm{M}$-current opener and blocked by an $\mathrm{M}$ current blocker. Finally, $\mathrm{CB}_{2} \mathrm{R}-\mathrm{cAMP}$ signaling plays a role in modulating DA neuron excitability since enhancement of cAMP by forskolin reduced $\mathrm{M}$-current and increased DA neuron firing rate.

\section{Implications of all the available evidence}

These results suggest that $\mathrm{CB}_{2}$ Rs modulate VTA DA neuron excitability through both synaptic and intrinsic mechanisms, including a reduction in presynaptic glutamate release and enhancement of postsynaptic neuronal M-currents. This work provides new insights into understanding the impact of brain CB2Rs in a variety of DA system associated disease pathogenesis and potential therapeutics.

brain regions [16,18-23]. Consistent with these findings, we reported that brain $\mathrm{CB}_{2} \mathrm{Rs}$ modulate cocaine self-administration, cocaineenhanced locomotion and extracellular dopamine (DA) levels in the nucleus accumbens in mice [24]. This finding was further supported by a study where mice over-expressing $\mathrm{CB}_{2}$ Rs exhibit a significantly lower level of cocaine self-administration and cocaine-enhanced locomotion compared to wild type (WT) mice [22]. Recently, we identified functional $\mathrm{CB}_{2} \mathrm{R}$ expression in mouse VTA DA neurons, and selective activation of these $C_{2}$ Rs reduced $D A$ neuronal excitability in vitro and in vivo preparations [25]. More recently, Stempel et al. reported that $\mathrm{CB}_{2} \mathrm{Rs}$ mediated a cell type-specific plasticity in the hippocampal CA3 neurons [11]. However, the cellular and molecular mechanisms underlying $\mathrm{CB}_{2} \mathrm{R}$ modulation of VTA DA neuronal excitability are poorly understood.

In the present study, we systematically investigated synaptic and intrinsic ionic channel mechanisms possibly underlying $\mathrm{CB}_{2} \mathrm{R}$ modulation of VTA DA neurons using patch-clamp recordings. We found that activation of VTA $\mathrm{CB}_{2}$ Rs reduced the frequency of mEPSCs but not mIPSCs in DA neurons. By using a perforated patch-clamp recording in acutely dissociated VTA DA neurons, a simple single cell model without intact presynaptic connections, we found that JWH133 reduced DA neuron action potential (AP) firing rate, prolonged AP initiation, enhanced afterhyperpolarization, and enhanced $\mathrm{M}$-type $\mathrm{K}^{+}$channel currents. In addition, we determined whether the presynaptic (reduction of mEPSC frequency) or postsynaptic (intrinsic) or both contribute to JWH133induced reduction in AP firing, and found that the intrinsic mechanism such as enhancement of M-current, contributes to $\mathrm{CB}_{2} \mathrm{R}$-mediated reduction of VTA DA neuronal excitability, which may play an important role in the regulation of DA-associated behaviors and diseases.

\section{Methods and materials}

\subsection{Animals}

Male wild-type (WT) and Zimmer strain $\mathrm{CB}_{2}^{-1-}$ mice [6,7] with C57BL/6J genetic backgrounds were bred at Barrow Neurological Institute. Genotyping was performed in our laboratory before experiments were begun. All experiments were in compliance with the Guide for the Care and Use of Laboratory Animals and experimental protocol has been approved by IACUC of Barrow Neurological Institute. When we tested the effects of $C B 2 R$ agonist on VTA DA neurons using $\mathrm{CB}_{2}^{-1-}$ mice, the littermate WT mice were used as the control. All experimental procedures were approved by the Institutional Animal Care and Use Committee at the Barrow Neurological Institute and by the Animal Ethics Committee of Qingdao University.

\subsection{VTA slice preparation}

Mice (14-31 days old) were used as previously described [26-28]. Briefly, mice were housed under standard conditions at $22-24{ }^{\circ} \mathrm{C}$ and $50-60 \%$ humidity under a $12 \mathrm{~h}$ light/dark cycle. On the experimental day, mice were anesthetized (isoflurane USP) and then sacrificed by decapitation. Horizontal (or coronal) midbrain slices $(250 \mu \mathrm{m})$ were cut using a vibratome 1000 (Vibratome 1000 plus; Jed Pella Inc., Redding, CA) to include the VTA. Slices were prepared in an ice-cold, sucrose-based, artificial cerebrospinal fluid containing (in $\mathrm{mM}$ ): 212.7 sucrose, $5 \mathrm{KCl}, 1.25 \mathrm{NaH}_{2} \mathrm{PO}_{4}, 3 \mathrm{MgCl}_{2}, 1 \mathrm{CaCl}_{2}, 26 \mathrm{NaHCO}_{3}$, and 10 glucose. The slices were then incubated for at least $1 \mathrm{~h}$ in a pre-incubation chamber (Warner Ins., Holliston, MA) at room temperature $\left(22-24^{\circ} \mathrm{C}\right)$ in conventional artificial cerebrospinal fluid containing (ACSF, in mM): $124 \mathrm{NaCl}, 5 \mathrm{KCl}, 2 \mathrm{CaCl}_{2}, 2 \mathrm{MgCl}_{2}, 1.25 \mathrm{NaH}_{2} \mathrm{PO}_{4}$, $26 \mathrm{NaHCO}_{3}$ and 10 glucose. The ACSF was continuously saturated with $95 \% \mathrm{O}_{2}$ and $5 \% \mathrm{CO}_{2}$.

\subsection{Cell-attached patch-clamp recordings in VTA slices}

For slice patch recordings, horizontal or coronal midbrain slices (250 $\mu \mathrm{m}$ thickness) were prepared from 14- to 31-day old mice (WT and $\mathrm{CB}_{2}^{-1-}$ ) mice as described previously [28]. To maintain an intact intracellular environment, we employed a cell-attached mode of patch recording. Thus, we were able to measure stable extracellular action 


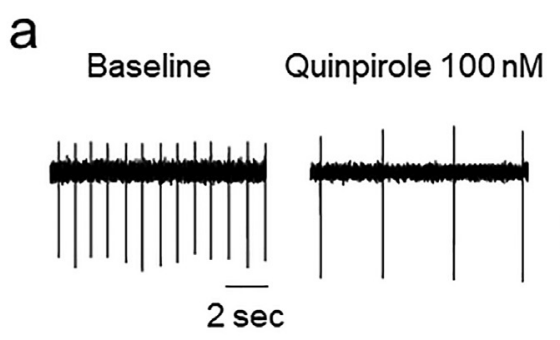

C

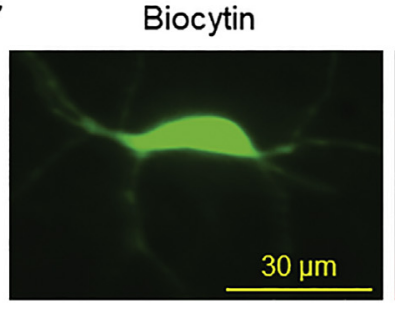

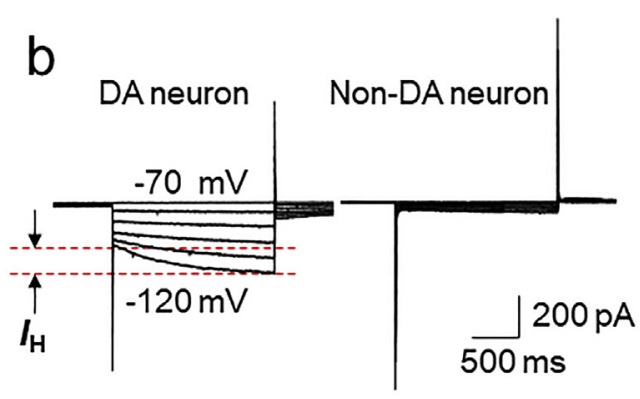

$\mathrm{TH}$

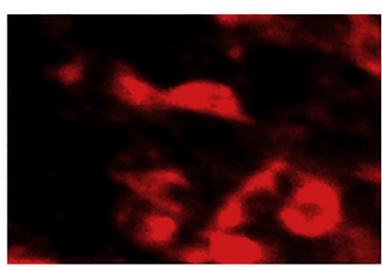

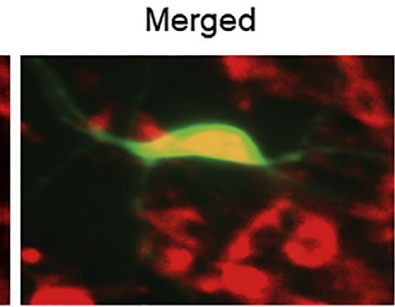

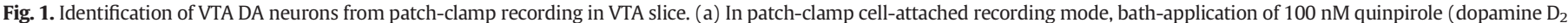

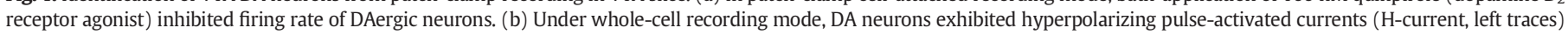

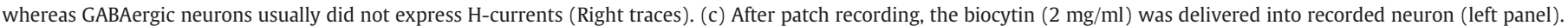
Tyrosine hydroxylase (TH) staining was performed post hoc and labels DA neurons (middle and right panels).

potential (AP) firing for hours. The recording pipette was filled with intracellular solution containing in mM: 140 potassium gluconate, $5 \mathrm{KCl}$, 10 HEPES, 0.2 EGTA, $2 \mathrm{MgCl}_{2}, 4 \mathrm{MgATP}, 0.3 \mathrm{Na}_{2} \mathrm{GTP}$ and $10 \mathrm{Na}_{2}-$ phosphocreatine ( $\mathrm{pH} 7.3$ with $\mathrm{KOH}$ ). After patch recording, we converted from cell-attached mode to conventional whole-cell recording to identify the neuronal phenotype of the recorded neuron according to standard electrophysiological, pharmacological and immunostaining criteria as described previously [28,29]. Briefly, in this study, we mostly recorded DA neurons from lateral VTA, which demonstrated a low action potential (AP) firing rate $(1-3 \mathrm{~Hz})$, large $\mathrm{H}$-current, and $\mathrm{TH}$ positive reaction by immunostaining (Fig. 1A-C). We have analyzed 12 VTA neurons (from 12 mice), under the cell-attached recording mode to record extracellular AP firing, the averaged AP duration was $2.34 \pm 0.07 \mathrm{~ms}$, the averaged firing rate was $1.65 \pm 0.14 \mathrm{~Hz}$, and after perfusion of $100 \mathrm{nM}$ quinpirole for $10 \mathrm{~min}$, the AP firing rate was reduced to 0.53 $\pm 0.08 \mathrm{~Hz}$ (paired $t$-test $p<0.0001$ ). After washout of quinpirole for $10 \mathrm{~min}$, AP firing rate recovered to $1.40 \pm 0.12 \mathrm{~Hz}$ (quinpirole washout $p<0.0001$ ). In addition, we have examined the effects of JWH133 on $\mathrm{H}-$ currents of DA neurons in mouse VTA slices. In 4 cells tested (from 2 mice), the amplitudes of $\mathrm{H}$-currents (hyperpolarizing from -60 to $-120 \mathrm{mV}$ ) before and after exposure of $10 \mu \mathrm{M}$ JWH133 for $10 \mathrm{~min}$ were $166.0 \pm 24.3 \mathrm{pA}$ and $161.3 \pm 11.2 \mathrm{pA}$ (paired $t$-test, $p=0.86$ ). These results suggest that acute application of $10 \mu \mathrm{M}$ JWH133 to VTA slices did not alter H-current.

\subsection{Miniature or evoked excitatory/inhibitory postsynaptic currents (mEPSCS/mIPSCS, eEPSCS/eIPSCS) in VTA slices}

To determine whether brain $\mathrm{CB}_{2}$ Rs modulate presynaptic glutamate or GABA release, thereby altering postsynaptic DA neuronal activity, we recorded mEPSCs in the presence of TTX (a voltage-dependent $\mathrm{Na}^{+}$ channel blocker, $1 \mu \mathrm{M}$ ), D-APV (a NMDA receptor antagonist, $50 \mu \mathrm{M}$ ) and picrotoxin (a selective $\mathrm{GABA}_{\mathrm{A}}$ receptor antagonist, $100 \mu \mathrm{M}$ ), or mIPSCs in the presence of TTX, NBQX (an AMPA receptor antagonist, $10 \mu \mathrm{M})$ and D-APV $(50 \mu \mathrm{M})$ in VTA DA neurons. In addition, we recorded electrical stimulation-evoked EPSCs (eEPSCs) or -evoked IPSCs (eIPSCs) in the absence of TTX to determine whether JWH133 alters eEPSCs or eIPSCs in VTA DA neurons.

\subsection{Patch-clamp recording from single dissociated VTA DA neurons}

Perforated-patch whole-cell recording techniques were employed $[30,31]$. Compared to performing conventional whole-cell recordings, this approach was crucial to obtain stable nicotinic responses from dissociated VTA neurons, presumably due to minimal perturbation of the intracellular environment. Pipettes (3-5 M $\Omega$ ) used for perforatedpatch recordings were filled with intracellular recording solution, which contained (in $\mathrm{mM}$ ): $140 \mathrm{~K}$-gluconate, $10 \mathrm{KCl}, 5 \mathrm{MgCl}_{2}$, and 10 HEPES; pH 7.2 (with Tris-OH) freshly supplemented before use with amphotericin B to $200 \mu \mathrm{g} / \mathrm{mL}$ from a $40 \mathrm{mg} / \mathrm{mL}$ DMSO stock. The liquid junction potential was $14 \mathrm{mV}$ and calculated using Clamplex 9.2 (Axon Instruments, Foster City, CA), and corrections were made for junction potentials post-hoc. After tight seal $(>2 G \Omega$ ) formation, about 5-20 min was required for conversion to the perforated-patch mode, and an access resistance of $<60 \mathrm{M} \Omega$ was accepted to start the experiments. Series resistance was not compensated in this study. Data were acquired at $10 \mathrm{kHz}$, filtered at $2 \mathrm{kHz}$, digitized on-line (Digidata $1440 \mathrm{se-}$ ries A/D board, Axon Instruments), and displayed and stored on a PC computer. Rapid application of drugs was performed using a computer-controlled "U-tube" system [30]. Periods of drug exposure are specified in the text and figures or legends. All experiments were performed at room temperature $\left(21 \pm 1{ }^{\circ} \mathrm{C}\right)$. To enable identification of single, dissociated VTA neurons, cells were labeled with biocytin (Sigma-Aldrich, St. Louis, MO; $2.0 \mathrm{mg} / \mathrm{mL}$ in the recording electrode) in some experiments. After conversion from perforated to a conventional whole-cell recording mode, the dye was injected into the cytoplasm by a pulse $(200 \mathrm{~ms}, 0.5 \mathrm{~Hz})$ of depolarizing current $(1.0 \mathrm{nA})$ for $3 \mathrm{~min}$. Labeled cells were visualized using epifluorescence microscopy (see detail in our recent publication) [25].

\subsection{Data analyses and statistics}

All data are presented as means ( \pm S.E.M.). One-way or two-way analysis of variance (ANOVA) was used to analyze the significance of the effects of JWH133 or other drugs on neuronal firing. Individual group comparisons were carried out using the Student Newman-Keuls or Tukey method. In addition, paired (or unpaired) $t$-tests were also 

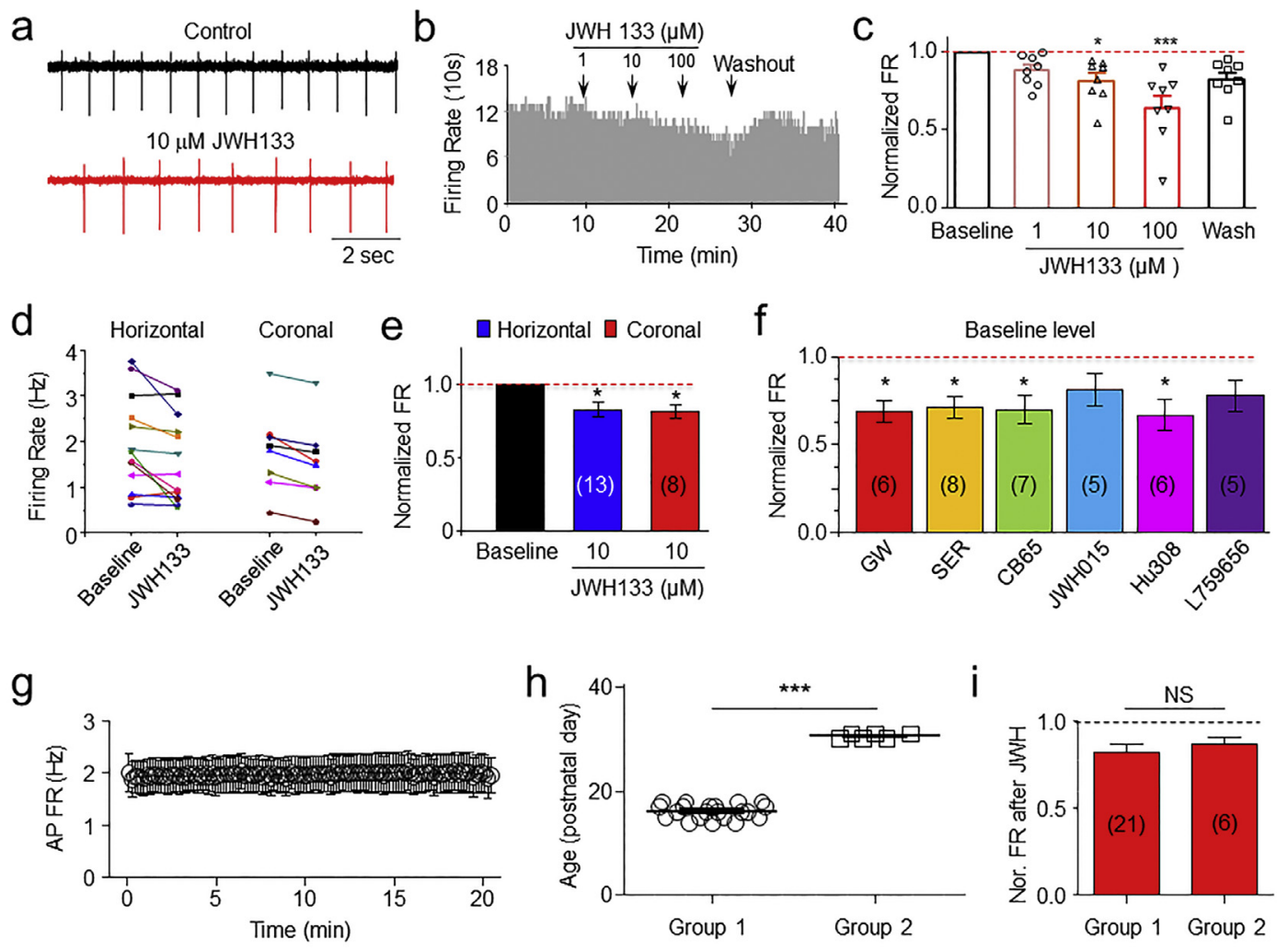

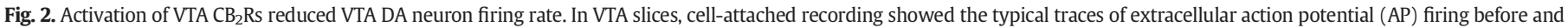

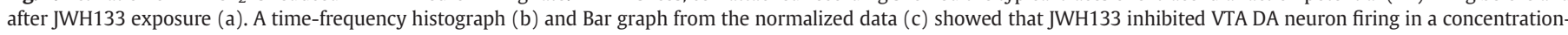

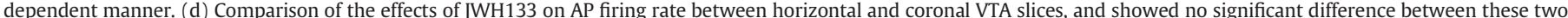

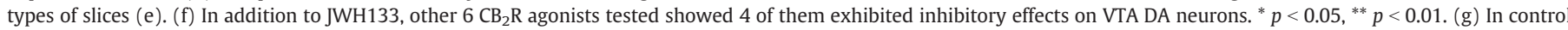

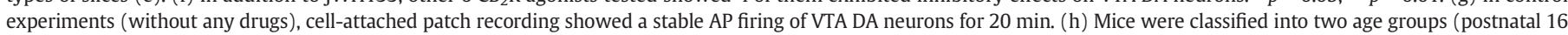
and 30). (i) Statistical comparison of JWH133 (10 $\mu \mathrm{M})$-induced inhibition of VTA DA neuron firing rate between these two age-groups, and showed no statistical significance (N.S.).

used to analyze some electrophysiological data as described previously [30,31].

\section{Results}

\subsection{Activation of CB2R reduced VTA DA neuron firing}

Initial experiments were designed to examine the concentrationdependent effect of $\mathrm{CB}_{2} \mathrm{R}$ agonist (JWH133) on VTA DA neuron firing using cell-attached recording mode. Fig. 2A shows a typical trace of VTA DA firing before (A top trace) and during (A bottom trace) $\mathrm{CB}_{2} \mathrm{R}$ agonist JWH133 exposure. Bath applications of different concentrations of JWH133 $(1,10,100 \mu \mathrm{M})$ reduced DA neuron firing rate in a concentration-dependent manner (Fig. 2B, C, One-way ANOVA, F $[4,35]$ $=6.97, p<0.001)$. Then, we examined the effects of JWH133 on DA neuron firing from horizontal ( $n=13$ from 4 mice) or coronal $(b=8$ from 3 mice) VTA slices, and found a modest but significantly consistent effect on inhibition of VTA DA neuron firing in both types of slice preparations (One-way ANOVA, $\mathrm{F}_{[2,31]}=4.79, p<0.05$, Fig. 2D, E). Further, Tukey analysis showed that compared to baseline, JWH133 inhibited DA fairing rate in either coronal ( $p<0.05, n=8$, Tukey analysis) or horizontal ( $p<0.05, \mathrm{n}=13$, Tukey analysis) slices. Furthermore, we tested whether different $C B_{2} R$ agonists exhibit similar inhibitory effects on VTA DA neuron firing. As shown in Fig. $2 \mathrm{~F}$, the $\mathrm{CB}_{2} \mathrm{R}$ agonists, $\mathrm{GW}$, SER, CB65, JWH105, Hu308 and L759656 exhibited a similar reduction of DA firing rate (One-way ANOVA, $\mathrm{F}_{[6,31]}=2.4, p<0.05$ ), but Tukey analysis showed that JWH105 and L759656 did not reach statistical significance ( $p>0.05$, Tukey analysis). Finally, to exclude the possibility that JWH133-induced reduction of AP firing rate was mediated by AP firing rundown with time, we performed a group of control experiments, in which, VTA DA neuronal AP firing was recorded using cell-attached patch for 20 min without any drugs. In 6 slices tested (from 3 mice), there was no functional rundown of AP firing within 20 min (Fig. 2G), demonstrating that cell-attached recording to measure extracellular AP firing was stable. Considering the ages of mice used in this study were between 2 and 4 weeks, we classified mice into two age groups and compared the effects of JWH133. Group one contained 21 slices with an average of age $16.1 \pm 0.3$ postnatal days and group two contained 6 slices with an average of $30.5 \pm 0.6$ postnatal days. The difference of the ages between these two groups were statistically significant $(p<0.001$, unpaired $t$-test, Fig. $2 \mathrm{H}) .10 \mu \mathrm{M}$ JWH133 inhibited VTA DA AP firing rate in a similar rate (Fig. 2I), in group one, the inhibitory rate was $18 \pm 4 \%$ ( $n=21$ from 8 mice), while in group two, the inhibitory rate was $15 \pm 3 \%$ ( $n=6$ from 2 mice, $p=0.59$, unpaired t-test), suggesting that during animal developing between P16 and P30, the $\mathrm{CB}_{2} \mathrm{R}$-mediated inhibition in VTA DA neuronal firing rate is not changed. Together, these results are further consistent with our previous findings that activation of VTA $\mathrm{CB}_{2}$ Rs reduces VTA DA neuron firing rate [25].

\subsection{Effects of $C_{2}$ R activation on excitatory synaptic transmission in VTA DA neurons}

VTA DA neuron firing is controlled by both presynaptic and postsynaptic mechanisms. To elucidate the mechanisms underlying $\mathrm{CB}_{2} \mathrm{R}-$ mediated reduction of VTA DA neuronal firing, we tested the effects of $\mathrm{CB}_{2} \mathrm{R}$ agonist on excitatory synaptic transmission measured by miniature excitatory postsynaptic currents (mEPSCs) in DA neurons of VTA slices. The identification of VTA DA neurons was based on their 
a
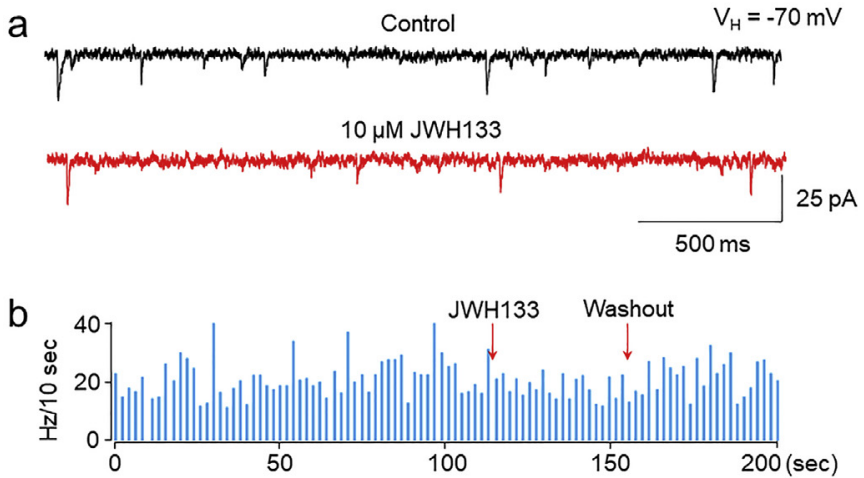

C

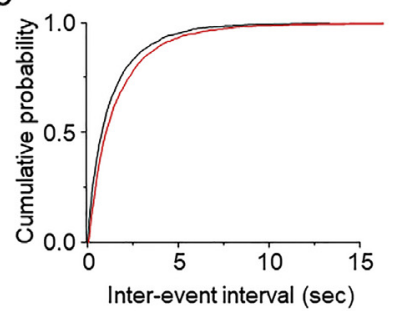

d
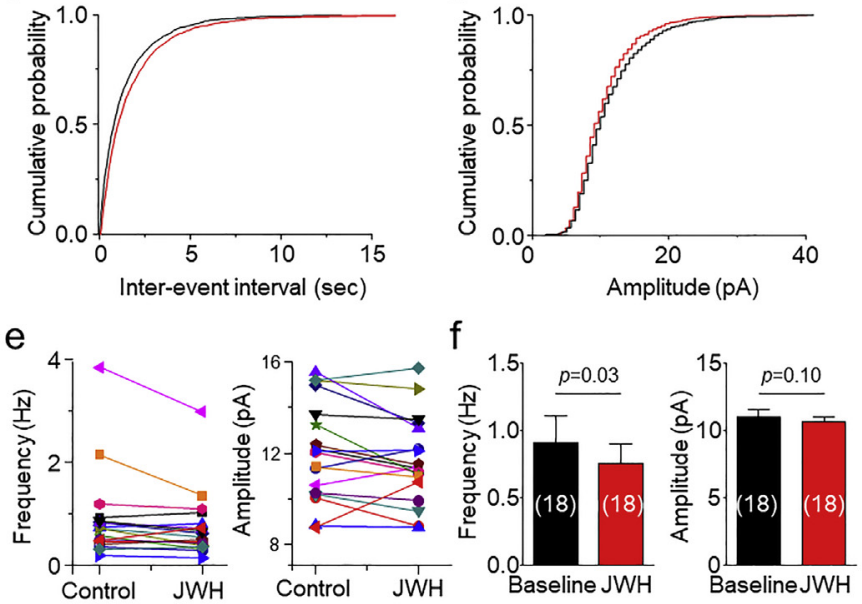

Fig. 3. Effects of JWH133 on excitatory synaptic transmission in VTA DA neurons. (a) Typical traces of mEPSCs in the presence of TTX $(1 \mu \mathrm{M})$ and picrotoxin $(100 \mu \mathrm{M})$ before (top trace) and after (bottom trace) JWH133 (10 $\mu \mathrm{M})$ exposure using whole-cell patch-clamp recording in a VTA slice. In 19 slices, cumulative probability analysis for mEPSC inter-event interval (b) and amplitude (c) under control conditions (black curve) and JWH133 exposure (red curve). (d) Comparison of mEPSC frequency (left panel) and amplitude (right panel) before and after JWH133 exposure from 19 VTA slices tested. (e) Bar graph data illustrating JWH133 significantly reduced mEPSC frequency, but not amplitude.

electrophysiological characteristic features and the TH staining after patch-clamp recording as described previously $[25,28]$ and shown in Fig. 1A-C. In 18 VTA slices tested prepared from 9 WT mice, bath perfusion of $10 \mu \mathrm{M}$ JWH133 for 10 min altered mEPSCs (Fig. 3A,B), represented as reduced frequency in 14 slices (Fig. 3C,E, left panel) and enhanced frequency in 4 slices. Averaged data showed that JWH133 reduced mEPSC frequency from $0.91 \pm 0.19$ to $0.75 \pm 0.14 \mathrm{~Hz}(p=0.03$, paired $t$-test, $n=18$, Fig. 3F, left panel). Further cumulative distribution of mEPSC inter-event interval showed significantly shift ( $\mathrm{K}-\mathrm{S}$ test, $p=$ 0.002 ). For mEPSC amplitude, JWH133 reduced amplitude in 3 slices and enhanced amplitude in 14 slices; and no change in 1 slice (Fig. 3D, $\mathrm{E}$, right panel), and together, there was no significant change of amplitude (from $11.0 \pm 0.5$ to $10.6 \pm 0.4 \mathrm{pA}, p=0.10$, paired t-test, $\mathrm{n}=$ 18 , Fig. $3 \mathrm{~F}$, right panel). These results suggest that acute activation of $\mathrm{CB}_{2}$ Rs shows a modest, but statistically significant, reduction in glutamatergic synaptic transmission in VTA DA neurons, including reduced presynaptic glutamate release probability.

\subsection{Effects of $C B_{2}$ R activation on inhibitory synaptic transmission in VTA DA neurons}

We then examined the effects of JWH133 on miniature inhibitory postsynaptic currents (mIPSCs) in the presence of TTX $(1 \mu \mathrm{M})$, NBQX $(10 \mu \mathrm{M})$ and D-APV $(50 \mu \mathrm{M})$. In 23 VTA slices prepared from $11 \mathrm{WT}$ a

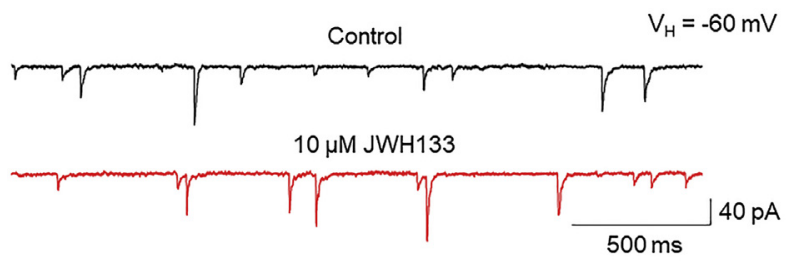

b
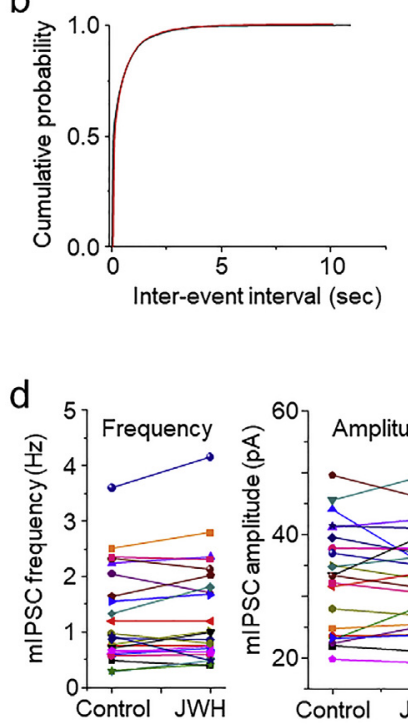

C

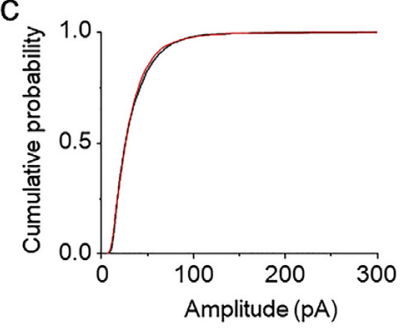

Fig. 4. Effects of JWH133 on inhibitory synaptic transmission in VTA DA neurons. (a) Typical traces of mIPSCs in the presence of NBQX $(10 \mu \mathrm{M})$ and D-APV $(50 \mu \mathrm{M})$ before (top trace) and after (bottom trace) JWH133 (10 $\mu \mathrm{M}$ ) exposure using the wholecell patch-clamp recording in a VTA slice. (b) and (c) In 23 VTA slices, cumulative probability analysis for mIPSC inter-event interval and amplitude under control conditions (baseline) and JWH133 exposure. K-S Test showed that JWH133 did not significantly alter both mIPSC frequency ( $p=0.432$, b) and amplitude $(p=0.384, \mathrm{c})$. (d) Comparison of mIPSC frequency (left panel) and amplitude (right panel) before and after JWH133 exposure from 23 VTA slices tested. (e) Normalized bar graph data illustrating JWH133 did not alter mIPSC frequency and amplitude.

mice, bath perfusion of $10 \mu \mathrm{M}$ JWH133 for 10 min altered mIPSC frequency and amplitude, represented as reduced frequency in 9 slices and enhanced frequency in 14 slices; reduced amplitude in 8 slices and enhancement amplitude in 14 slices; and no change in one slice. After averaged, these data showed that after JWH133 exposure, mIPSC frequency was $109 \%(109 \pm 5 \%, p=0.09$, paired $t$-test, $n=$ 23) and amplitude was $101 \%$ (101 $\pm 2 \%, p=0.73$, paired t-test, $n$ $=23$ ) compared to the baseline level (Fig. 4A, E). Neither interevent interval nor amplitude cumulative distribution showed shift (Fig. $4 \mathrm{~B}, \mathrm{C}$ ). These results suggest that activation of $\mathrm{CB}_{2} \mathrm{Rs}$ exhibits little effects on either presynaptic GABA release or postsynaptic $G_{A B A_{A}}$ receptor function.

\subsection{Effects of $C B_{2}$ R activation on evoked EPSCs and IPSCs in VTA DA neurons}

We also examined the effects of JWH133 on evoked EPSCs (eEPSCs) and IPSCs (eIPSCs). In these experiments, $100 \mu \mathrm{M}$ PTX (for eEPSCs) or NBQX $(10 \mu \mathrm{M})+$ APV $(50 \mu \mathrm{M})$ (for eIPSCs) was added into the bath solution. A bipolar tungsten stimulation electrode was placed at $\sim 150 \mu \mathrm{m}$ rostral to the recording electrode and the paired stimulation pulses with $50 \mathrm{~ms}$ interval were applied (Fig. 5A). The results showed that bath perfusion of $10 \mu \mathrm{M}$ JWH133 for 10 min failed to alter the current amplitude and the P2/P1 ratio of paired-pulseinduced eEPSCs (Fig. 5A-C) and eIPSCs (Fig. 5D-F). These results suggest that acute activation of VTA $\mathrm{CB}_{2}$ Rs does not affect evoked synaptic neurotransmitter release. 
a
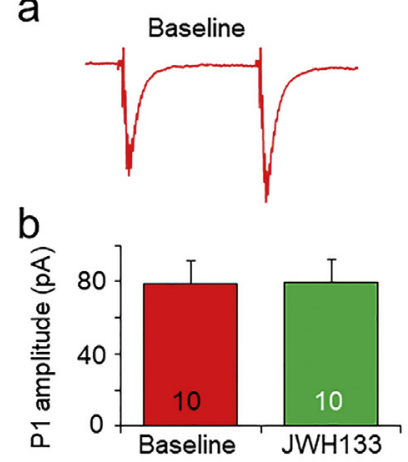

eEPSCs

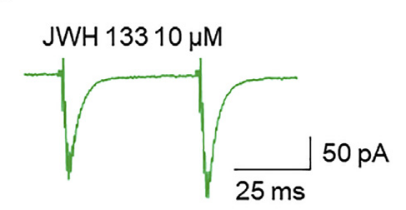

d

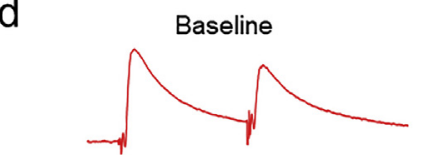

e

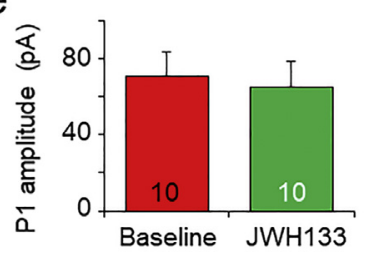

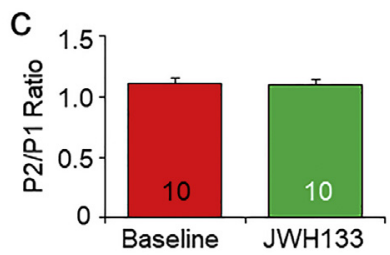

elPSCs

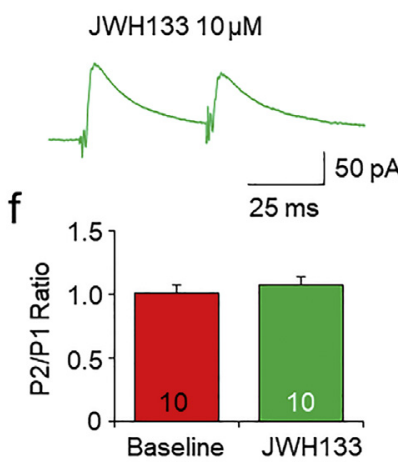

Fig. 5. Effects of JWH133 on evoked EPSCs and IPSCs in VTA DA neurons. (a) Representative typical traces of paired-pulse (50 ms interval) stimulation-induced eEPSCs before (left trace pair) and after (right trace pair) exposure to JWH133. Bar graph illustrating that JWH133 $(10 \mu \mathrm{M})$ altered neither eEPSC amplitude (b) nor P2/P1 ratio (c) in 10 VTA slices tested. (d) Representative typical traces of paired-pulse (50 ms interval) stimulation-induced eIPSCs before (left trace pair) and after (right trace pair) exposure to JWH133. Bar graph illustrating that JWH133 $(10 \mu \mathrm{M})$ did not change eIPSC amplitude (e) and P2/P1 ratio (f) in 10 VTA slices tested.

\subsection{Characteristic features of $C B_{2} R$-mediated modulation in VTA DA neuron action potentials}

The data presented thus far demonstrated that a mild reduction of presynaptic glutamatergic by acute $\mathrm{CB}_{2} \mathrm{R}$ activation. We further elucidated possible intrinsic mechanisms of the $\mathrm{CB}_{2} \mathrm{R}$-mediated modulation in postsynaptic DA neurons. To accomplish this, we used freshly dissociated single VTA DA neurons, which is a pure postsynaptic cell model since the enzymatic treatment and mechanical dissociation remove all presynaptic terminals/boutons from these cells [25,30,31]. Perforated (amphotericin B) patch-clamp recording from the single dissociated VTA DA neurons showed that bath application of $1 \mu \mathrm{M}$ JWH133 for 1-3 min reduced AP firing rate (Fig. 6A-C), prolonged AP initiation (Fig. 6D) and enhanced the amplitude of after-hyperpolarization current (Fig. 6E). Fig. 6F summarizes these AP alterations before, during and after exposure to JWH133. These results suggest that, in a single neuron model, the activation of somatodendritic $\mathrm{CB}_{2}$ Rs in VTA DA neurons reduces neuronal excitability likely via alterations of intrinsic ion channels such as the M-type $\mathrm{K}^{+}$channels.

\subsection{Effects of $\mathrm{CB}_{2} R$ agonist on voltage-dependent $M$-type $\mathrm{K}^{+}$currents}

M-channel is a voltage-gated, non-inactivating $\mathrm{K}^{+}$channel. It is expressed in VTA DA neurons [32] and functionally modulates neuronal excitability [33,34]. It has been reported that M-channels are modulated by multiple G-protein-coupled receptors, including $\mathrm{CB}_{1} \mathrm{Rs}$ [35].

Therefore, we explored the possibility that $\mathrm{CB}_{2} \mathrm{Rs}$ may also modulate $\mathrm{M}$-currents in VTA DA neurons. M-currents were induced with a standard deactivation voltage protocol $[32,36]$ as shown in Fig. 7A. Mcurrent is measured as the inward relaxation current caused by Mcurrent deactivation during the voltage steps. Bath-applied JWH133 (1 $\mu \mathrm{M}$ ) significantly enhanced M-currents elicited by three hyperpolarizing holding potentials in dissociated VTA DA neurons in WT mice (Fig. 7B), and this effect was reversible after JWH133 washout (Fig. 7C). Fig. 7D shows the superimposed traces of M-currents before and during JWH133 exposure, showing a JWH133-induced M-current augmentation. This effect was blocked by AM630 $(1 \mu \mathrm{M})$ and absent in VTA DA neurons prepared from $\mathrm{CB}_{2}^{-1-}$ mice. To confirm the identity of the recorded M-current, we examined the effects of retigabine (a selective M-current enhancer, $10 \mu \mathrm{M}$ ) and XE991 (a selective M-current blocker, $30 \mu \mathrm{M})$ on the recorded current. Like JWH133, retigabine enhanced ( $n=5$ from 3 mice, $p=0.02$, paired $t$-test), but XE991 reduced ( $n=8$ from 4 mice, $p=0.003$, paired t-test) the recorded currents produced by the M-current-inducing protocol, supporting the conclusion that the recorded currents were, indeed, M-currents. Fig. 7E shows pooled data, illustrating the effects of each individual group tested, in which JWH133 $(1 \mu \mathrm{M})$ enhanced M-currents ( $n=19$ from 8 mice, $p$ $=0.0002$, paired t-test), AM630 + JWH133 abolished JWH133's effect, retigabine enhanced but XE991 reduced M-currents in WT mice. While in $\mathrm{CB}_{2}^{-1-}$ mice, JWH133 failed to enhance M-current but retigabine still enhances and XE991 still reduced M-currents. These results suggest that the inhibitory effect of JWH133 on M-current is mediated through the $\mathrm{CB}_{2} \mathrm{Rs}$, while the effects of retigabine and XE991 on M-current are $\mathrm{CB}_{2} \mathrm{R}$-independent.

\subsection{Roles of $\mathrm{CB}_{2} R$-mediated enhancement of $M$-current in altered VTA DA} neuron firing

To further determine whether JWH133-enhanced M-currents contribute to JWH133-induced VTA DA neuronal inhibition, we examined the effects of retigabine and XE991 on VTA DA neuronal firing. In single dissociated VTA DA neurons, we found that retigabine $(10 \mu \mathrm{M})$ increased M-currents, in an amplitude similar to JWH133, causing a reduction in VTA DA neuronal firing, while XE991 (30 $\mu \mathrm{M})$ attenuated M-currents, producing an increase in neuronal firing (Fig. 8A, B). Fig. $8 \mathrm{C}$ and $\mathrm{D}$ show the summarized results after statistical analyses that retigabine reduced AP firing rate and prolonged AP initial time, and XE991 increased AP firing rate and shorted AP initial time. These results suggest that M-current in VTA DA neurons play an important role in modulation of neuronal firing rate. In VTA slices, cell-attached recordings showed that, in the presence of XE991, JWH133 failed to inhibit DA neuron firing (Fig. 8E, F). These results suggest that JWH133-enhanced M-currents play a role in the JWH133-induced reduction in VTA DA neuronal firing.

\subsection{Intracellular signal pathway of JWH133-induced enhancement of M-current}

In these experiments, we determined which second messenger molecule mediates the $\mathrm{CB}_{2} \mathrm{R}-\mathrm{G}$-protein signaling to M-type $\mathrm{K}^{+}$channels. It is known that $\mathrm{CB}_{2} \mathrm{R}$ activation primarily initiates two signal pathways, MAPK/ERK and CAMP/PKA, producing an increase in the former and decrease in the latter [37-39]. Since cAMP, but not MAPK, is associated to M-type $\mathrm{K}^{+}$channels [37,40], we examined the effect of enhanced intracellular cAMP by forskolin on JWH133-induced enhancement of Mcurrent. As shown in Fig. 9, bath-perfusion of $10 \mu \mathrm{M}$ forskolin to dissociated single VTA DA neuron reduced M-current by $19.2 \pm 4.9 \%$ and in the presence of forskolin, JWH133 $(1 \mu \mathrm{M})$ potentiated M-current by $8.1 \pm$ $3.7 \%$ ( $n=10$ from 5 mice, One-Way ANOVA, $\mathrm{F}_{[3,27]}=14.9, p<$ 0.0001 ). Further analysis showed that forskolin-induced reduction of M-current was significant ( $p<0.01$, One-way ANOVA, Tukey), while in the presence of forskolin, JWH133-induced change of AP firing was 

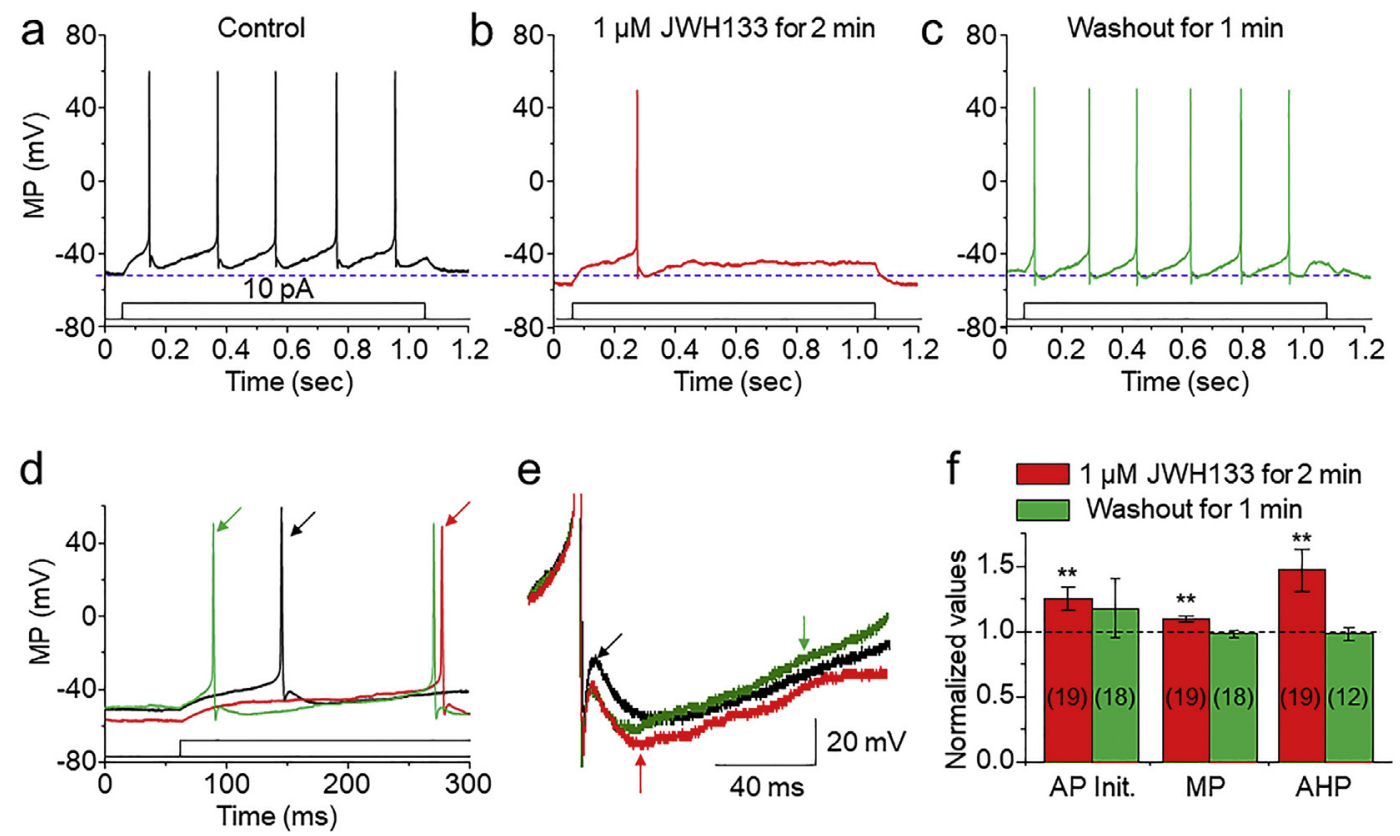

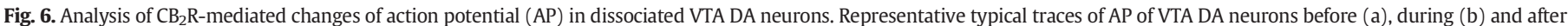

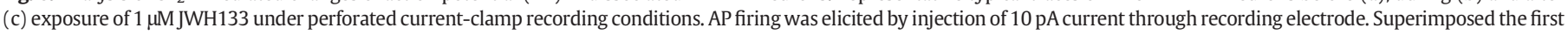

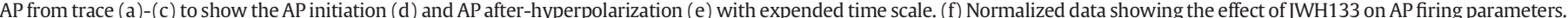
${ }^{*} p<0.05,{ }^{* *} p<0.01$.
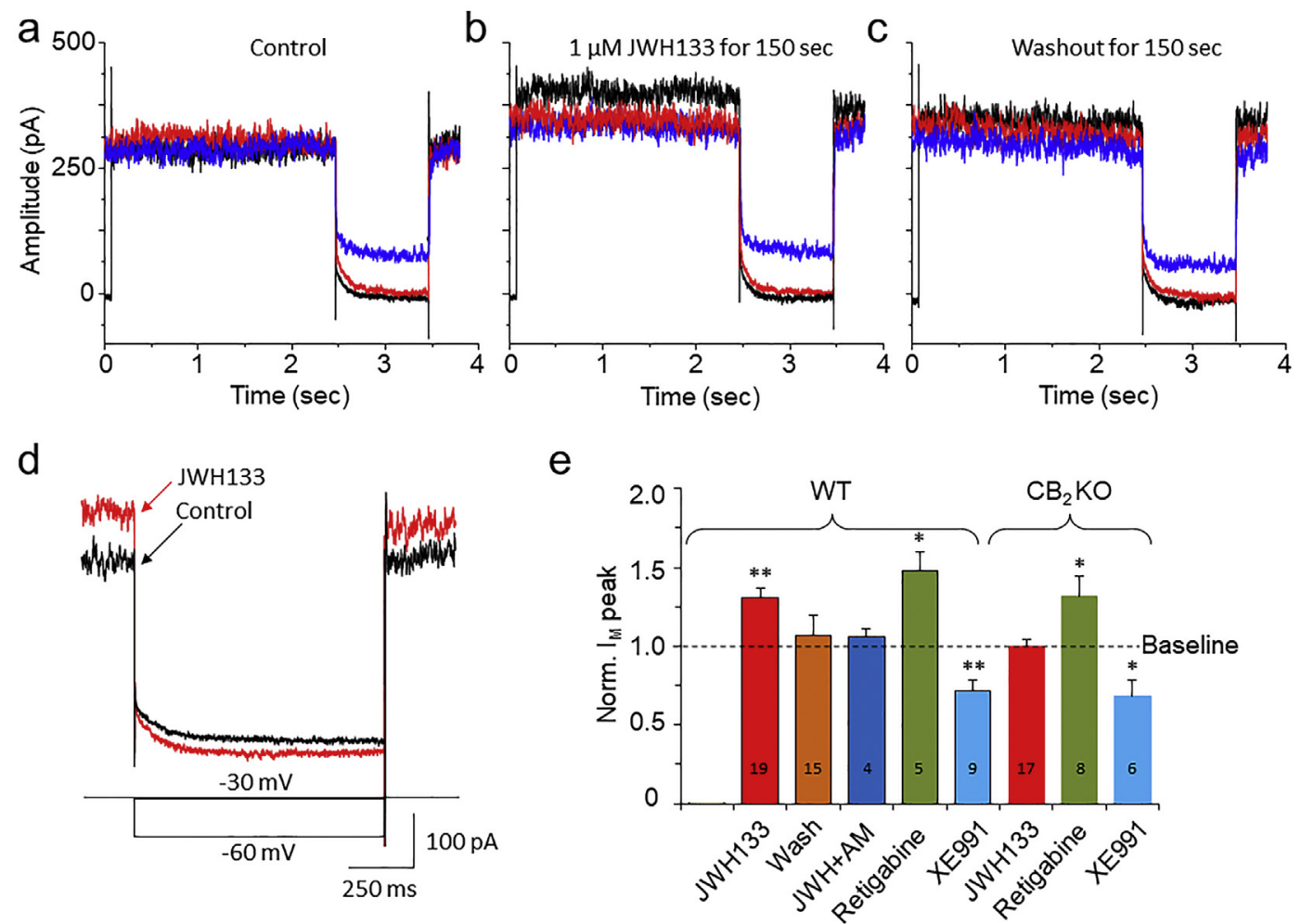

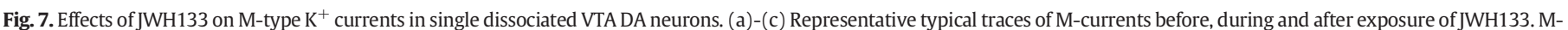

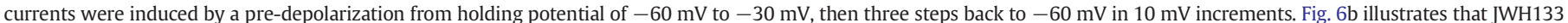

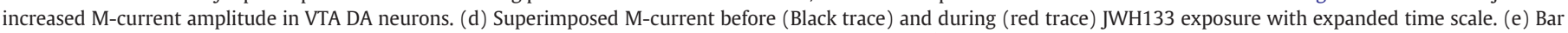

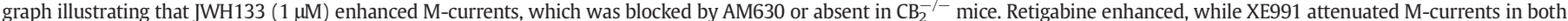

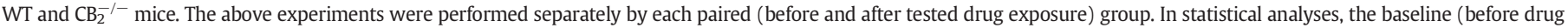
exposure) was normalized as 1 , and the changed value after drug perfusion was compared to the baseline of each individual group, and analyzed using paired $t$-test. 
a
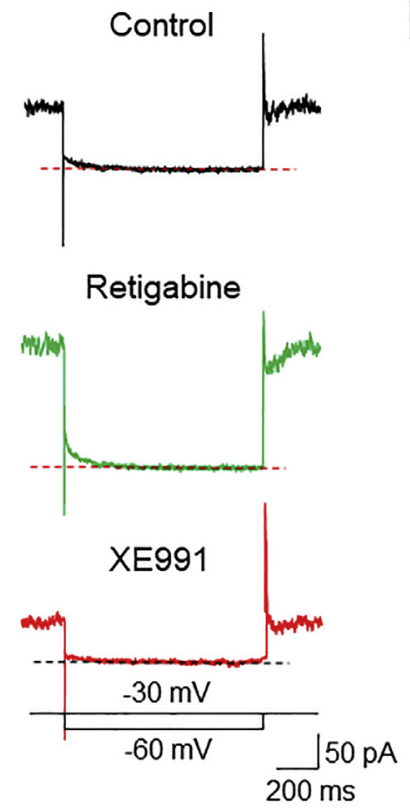

C

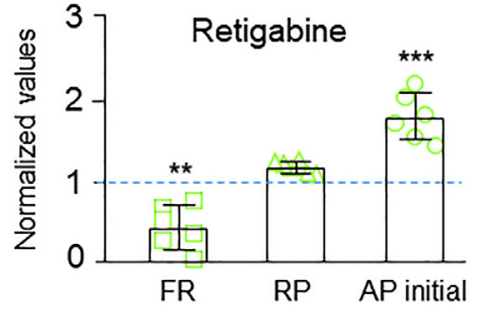

e

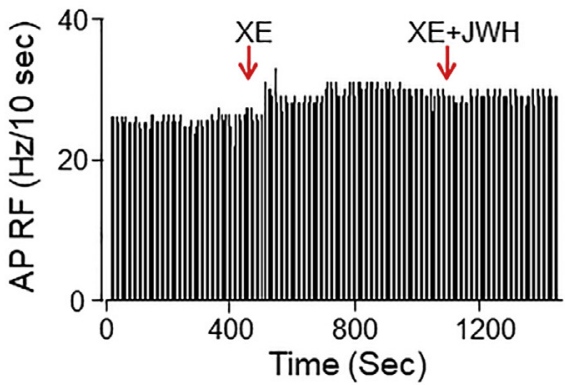

b
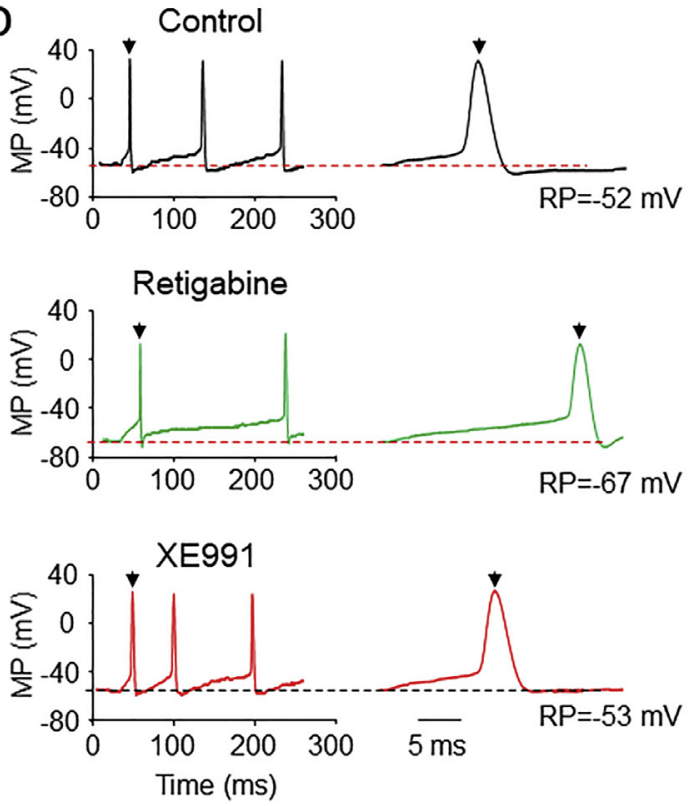

d

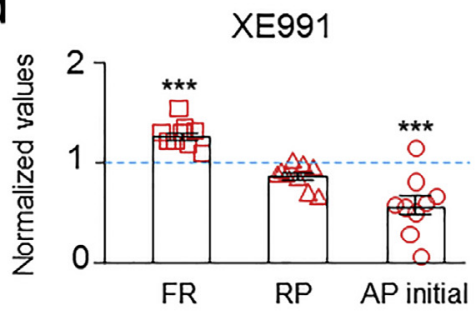

$f$

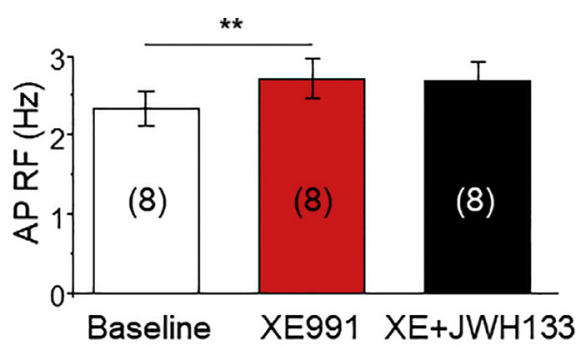

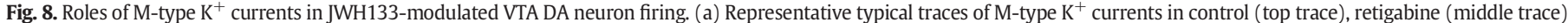

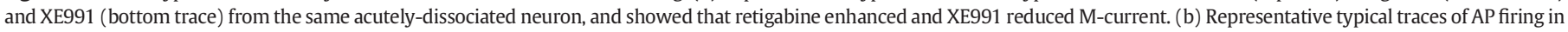

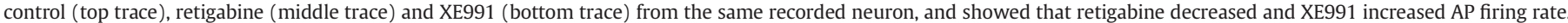

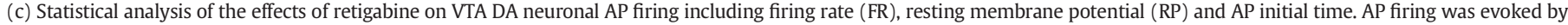

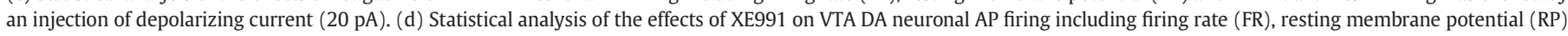

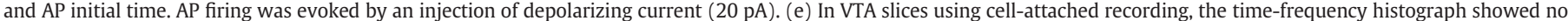
detectable change of AP firing rate after exposure to XE991 plus JWH133. (f) Statistical analysis showed JWH133 failed to reduce VTA DA firing rate in the presence of XE991.

not significant ( $p>0.05$, Fig. 9A,B, One-way ANOVA, Tukey). These results suggest that $\mathrm{CB}_{2} \mathrm{R}$-mediated reduction of intracellular cAMP likely contributes to the enhancement of M-current by JWH133. Finally, we determined whether forskolin can prevent the JWH133-induced DA firing reduction. As shown in Fig. 9C and D, using cell-attached recording in VTA slices, bath-application of forskolin $(10 \mu \mathrm{M})$ increased DA firing rate and prevented JWH133 $(10 \mu \mathrm{M})$-mediated reduction of DA firing rate $\left(n=11\right.$ from 5 mice, One-way ANOVA, $\mathrm{F}_{[2,20]}=4.63, p=0.018$, Fig. 9C, D). Further analysis showed that forskolin increased AP firing rate by $8.2 \pm 2.0 \%(p<0.05$, paired $t$-test $)$, while in the presence of forskolin, JWH133 altered AP firing by $1.2 \pm 3.0 \%(p>0.05$, paired $t-$ test). Together, these results suggest that JWH133 activates $\mathrm{CB}_{2} \mathrm{R}-\mathrm{G}$ protein signaling, thereby reducing intracellular cAMP levels, in turn enhancing $\mathrm{M}$-type $\mathrm{K}^{+}$channel function, and ultimately reducing VTA DA neuronal excitability.

3.9. Do both synaptic and intrinsic mechanisms contribute to $C B 2 R$ mediated reduction of VTA DA neuron firing?

To further determine the above findings that presynaptic mechanism (reduced mEPSC frequency) and intrinsic mechanism (enhanced $\mathrm{M}$-current) contribute to $\mathrm{CB}_{2} \mathrm{R}$-mediated inhibition in VTA DA neuronal firing, we designed two additional experiments. First, we examined the effects of JWH133 on neuronal firing in the presence of NBQX $(10 \mu \mathrm{M})$, APV $(50 \mu \mathrm{M})$ and picrotoxin $(100 \mu \mathrm{M})$ to block excitatory and inhibitory presynaptic transmissions. We found that under cell-attached recording 

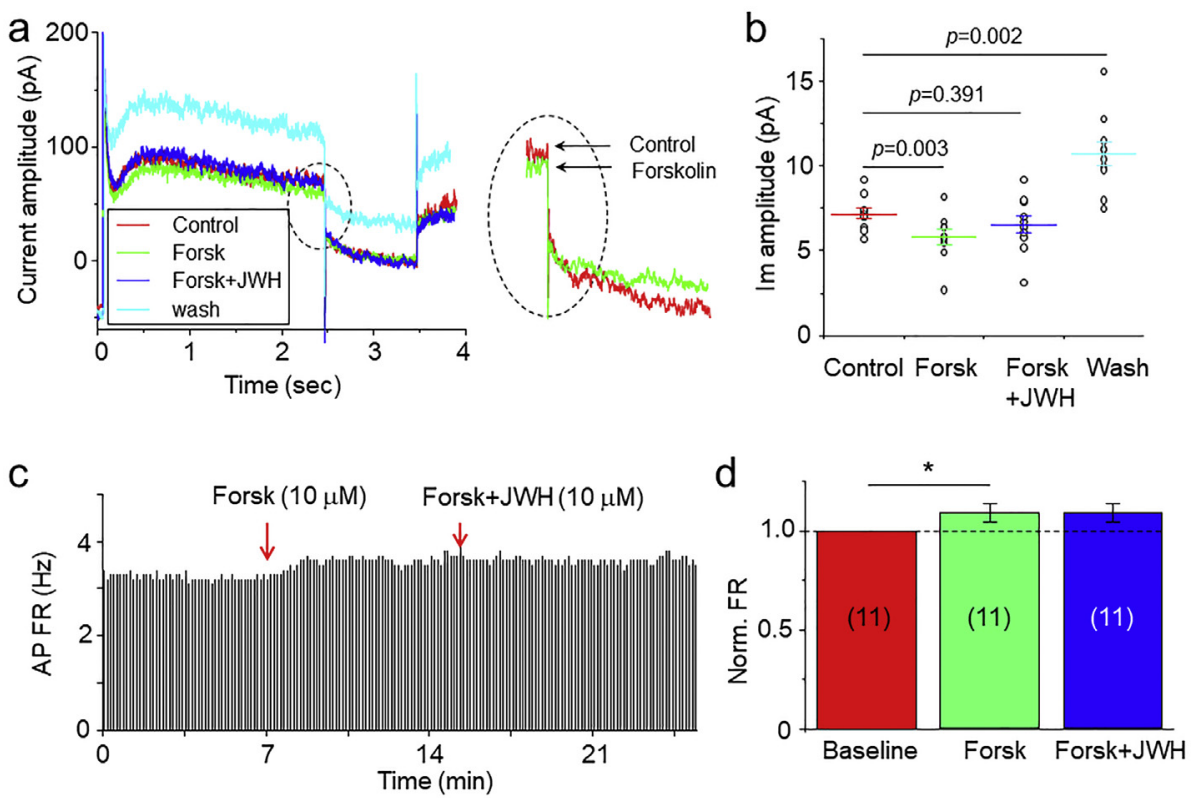

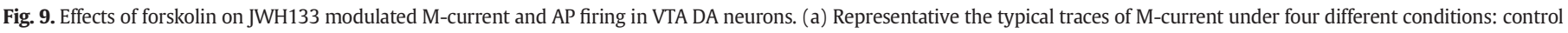

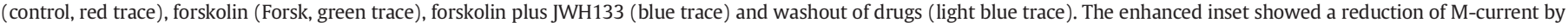

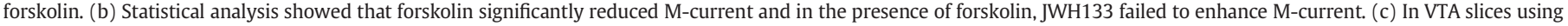

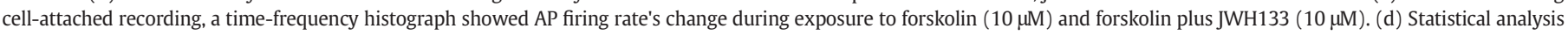
showed that forskolin increased AP firing rate, and in the presence of forskolin, JWH133 failed to reduce AP firing rate.

mode, JWH133 (10 $\mu \mathrm{M})$ still significantly reduced DA neuron AP firing rate (inhibitory rate was $11 \pm 2 \%, n=21$ from 6 mice, $p=0.0001$, paired $t$-test, Fig. 10A), while without this pharmacological cocktail, JWH133-induced reduction in AP firing rate was $18 \pm 4 \%(n=21$ from 8 mice, $p=0.0002$, Fig. 10B). Although the block of synaptic transmission did reduce the inhibitory rate by JWH133 from $18 \pm 4 \%$ (without synaptic block) to $11 \pm 2 \%$ (with synaptic block), the difference of the inhibitory rate between these two groups ( $18 \pm 4 \%$ vs. $11 \pm 2 \%$ ) was not statistical significant ( $p=0.165$, unpaired t-test). These results suggest that JWH133-induced mild reduction of presynaptic glutamate release seems not to play an important role in the mediation of JWH133-induced reduction in DA neuron firing. Second, we selectively blocked postsynaptic $\mathrm{CB}_{2} \mathrm{R}-\mathrm{G}$ protein function by addition of $600 \mu \mathrm{M}$ GDP- $\beta-S$, an intracellular $G$-protein blocker, into the recording electrode, thus allowing GDP- $\beta-S$ to infuse into the recorded neuron after converted into whole-cell recording mode. As shown in Fig. 10, in the presence of intracellular GDP- $\beta S$, bath application of $10 \mu \mathrm{M}$ JWH133 failed to alter AP firing rate in VTA DA neurons (from $1.97 \pm 0.39$ to $2.03 \pm 0.44 \mathrm{~Hz}, p=0.44$, paired t-test, $n=7$ from 3 mice, Fig. 10C). However, in the absence of intracellular GDP- $\beta S$, bath application of $10 \mu \mathrm{M}$ JWH133 reduced VTA DA neuronal rate (from $1.99 \pm 0.23$ to $1.70 \pm 0.22 \mathrm{~Hz}, p=0.004$, paired t-test, $n=14$ from 4 mice, Fig. 10D). Statistical analysis showed that under whole-cell recording conditions (within 5 min after converted into whole-cell configuration), JWH133 failed to reduce AP firing rate in the presence of intracellular GDP-BS (Fig. 10E), while JWH133 reduced AP firing in the group neurons that did not contain intracellular GDP-BS (Fig. 10F). These results suggest that the intrinsic mechanism $\left(\mathrm{CB}_{2} \mathrm{R}\right.$-mediated enhancement of M-current) predominantly underlies the JWH133-induced reduction of VTA DA neuron excitability.

\section{Discussion}

In this study, we find that acute exposure of the $\mathrm{CB}_{2} \mathrm{R}$ agonist, JWH133, reduces DA neuronal excitability in the VTA, which is mainly mediated through an intrinsic mechanism. Although JWH133 mildly reduces presynaptic glutamate release probability and results in a decreased glutamatergic synaptic transmission in VTA DA neurons, this may play little role in JWH133-induced reduction of VTA DA neuron firing because pharmacological block of synaptic transmission fails to prevent JWH133induced inhibitory effect. JWH133 activates a postsynaptic $\mathrm{CB}_{2} \mathrm{R}-\mathrm{G}_{\mathrm{i} / \mathrm{o}}$ signaling cascade, reduces intracellular cAMP levels, in turn enhances M-type $\mathrm{K}^{+}$channel function, and leading to the reduction of VTA DA neuronal excitability. Through this intrinsic mechanism, $\mathrm{CB}_{2} \mathrm{Rs}$ significantly reduce VTA DA neuronal excitability, which may underlie $\mathrm{CB}_{2} \mathrm{R}$-mediated modulations in mesolimbic DA system function and DA-related behavior and diseases.

VTA DA neuronal firing is controlled by excitatory and inhibitory synaptic innervations. Modulations of these synaptic inputs alter neuronal excitability. Numerous G-protein-coupled receptors such as opioid, $5-\mathrm{HT}_{2}$, metabolic glutamate, $\mathrm{GABA}_{\mathrm{B}}$ and $\mathrm{CB}_{1}$ receptors modulate synaptic transmission by alteration of presynaptic neurotransmitter release. Emerging evidence demonstrates that activation of $\mathrm{CB}_{2}$ Rs modulates synaptic transmission in the entorhinal cortex [41], transfected hippocampal Duald neurons [42] and hippocampal pyramidal neurons from hippocampal slice cultures [43]. Thus, it is reasonable that $\mathrm{CB}_{2} \mathrm{Rs}$ are expressed in presynaptic terminals/boutons and modulate neurotransmitter release. Indeed, in this study, we found a mild, but statistically significant, reduction in the frequency of MEPSC after exposure to JWH133 $(10 \mu \mathrm{M})$, suggesting that JWH133-induced reduction in VTA DA neuronal excitability may be mediated, at least in part, through a reduction of glutamatergic synaptic transmission onto DA neurons. However, additional experiments showed that pharmacological block of glutamatergic and GABAergic transmissions by perfusion of NBQX, APV and picrotoxin to VTA slice failed to prevent JWH133 $(10 \mu \mathrm{M})$ induced reduction in DA neuron firing rate. These results suggest that JWH133-induced the mild reduction of presynaptic glutamate release does not contribute to the JWH133-induced reduction in DA neuron firing under our experimental conditions. Previous report has shown that the activation of $\mathrm{CB}_{2}$ Rs reduced inhibitory synaptic transmission in the entorhinal cortex [41], but this study did not identify the cellular location of the $\mathrm{CB}_{2}$ Rs involved [41]. Thus, the pharmacological effects 

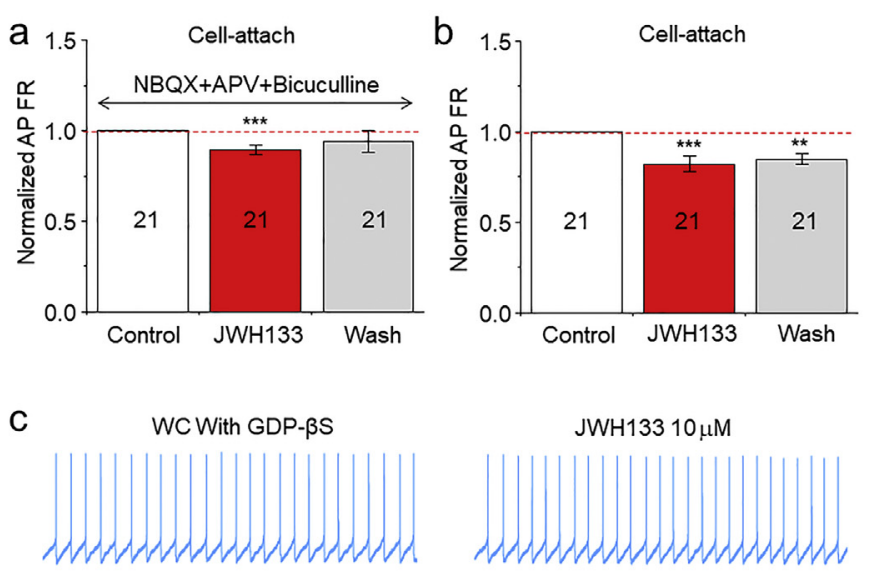

d

WC without GDP-ßS
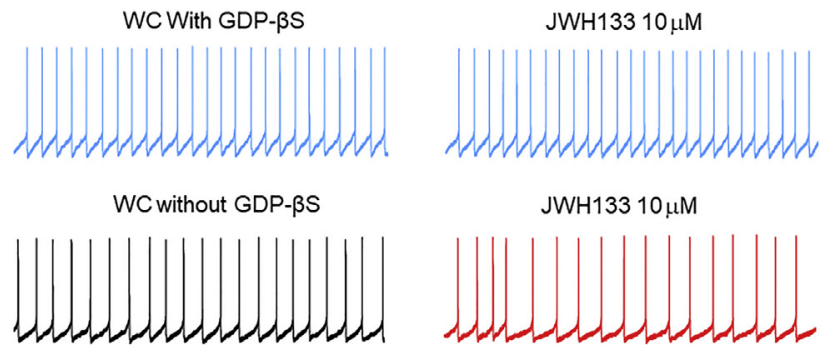

e

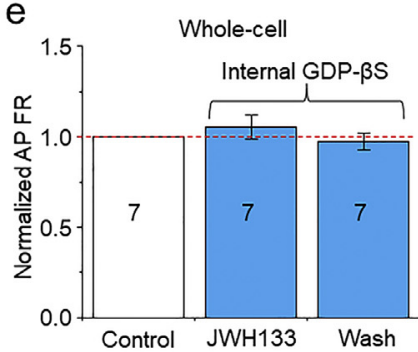

f

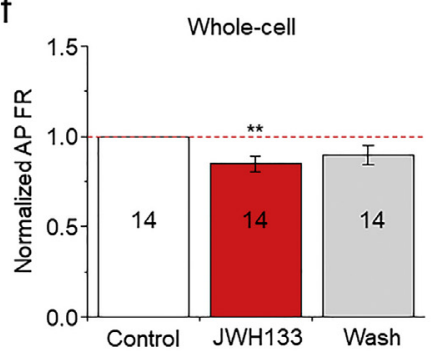

Fig. 10. Determination of the role of synaptic and intrinsic mechanisms in JWH133induced reduction of VTA DA neuronal excitability. (a) Bar graph summarizes data that showed the alteration of AP firing rate before and after JWH133 exposure. The VTA DA neuron AP firing was recorded using cell-attach recording mode in the presence (a) and absence (b) of and of cocktail pharmacology (NBQX + APV + PTX) to block synaptic transmission. (c) Representative typical traces showing the AP firing measured by whole-cell recordings in current-clamp mode before (left) and after (right) JWH133 exposure. In these experiments, the GDP- $\beta S(600 \mu \mathrm{M})$ was added into recording electrode, and converted to whole-cell recording mode allowed GDP- $\beta S$ infusion into recorded cells, and data showed that JWH133 failed to alter AP firing rate. (d) Representative typical traces in control group showing the AP firing measured by whole-cell recordings in current-clamp mode before (left) and after (right) JWH133 exposure without GDP- 3 S in the pipette solution and showed that JWH133 reduced AP firing rate. (e)/(f) Bar graph summarizes pooled data from (c) and (d) demonstrating that JWH133 significantly reduced AP firing rate in control (d), but not GDP-BS-treated neurons (c). ${ }^{* *} p<0.01,{ }^{* * *} p<0.001$, compared to AP firing before JWH133 exposure.

reported may be caused by $\mathrm{CB}_{2} \mathrm{Rs}$ expressed in either cortical neurons or microglia [44] since microglia are capable of modulating synaptic plasticity [45]. Another report demonstrated that selective activation of neuronal $\mathrm{CB}_{2} \mathrm{Rs}$ reduced inhibitory synaptic transmission via a presynaptic mechanism in transfected hippocampal Duald neurons prepared from $\mathrm{CB}_{1} \mathrm{R}^{-1-}$ mice [42]. Compared to these two reports, we found that $\mathrm{CB}_{2} \mathrm{Rs}$ mildly reduced glutamatergic, but not GABAergic transmission in mouse VTA DA neurons. This discrepancy may be due to several reasons. First, different brain regions or neuronal phenotypes may have varied levels of $\mathrm{CB}_{2} \mathrm{R}$ expression [46]. This is supported by our recent finding that $\mathrm{CB}_{2} \mathrm{Rs}$ are highly expressed in the midbrain and moderately expressed in the prefrontal cortex (PFC), while the expression in the striatum is very low [25]. Second, brain $\mathrm{CB}_{2} \mathrm{R}$ expression is inducible and dynamic. For example, repeated cocaine administration or selfadministration significantly up-regulates brain $\mathrm{CB}_{2} \mathrm{R}$ expression in the PFC, striatum and midbrain, as well as VTA neurons in rats [47]. Similarly, chronic, rather than acute, treatment of the slices with JWH133 for 7 days significantly enhanced excitatory synaptic transmission,

suggesting that chronic treatment of JWH133 may up-regulate $\mathrm{CB}_{2} \mathrm{R}$ expression in the hippocampus [43]. Third, different $\mathrm{CB}_{2} \mathrm{R}$ agonists, with varying pharmacological actions, were used in separate studies. These pharmacological variances, resulting in the activation of diverse intracellular signal pathways [48], may explain these inconsistent electrophysiological findings. Collectively, our data suggest that glutamatergic presynaptic terminal/boutons may express very low level of $\mathrm{CB}_{2} \mathrm{Rs}$, where they mildly modulate glutamate release probability, but contribute little to the alteration of DA neuron firing rate. Interestingly, we did not see a significant effect of JWH133 on mIPSCs, eEPSCs and eIPSCs in VTA DA neurons, which is consistent with previous report that activation of $\mathrm{CB}_{2}$ Rs modulated glutamatergic, but not GABAergic synaptic, transmission in hippocampal slices [43]. The reason remains unknown, it may suggest that $\mathrm{CB}_{2}$ Rs are mainly distributed on the neuron somato, and only limited $\mathrm{CB}_{2}$ Rs are expressed on glutamatergic presynaptic terminals/boutons in VTA DA neurons. Our previous work supports this idea [25] as we showed predominant expression of $\mathrm{CB}_{2}$ Rs on the VTA DAergic cell body.

In addition to presynaptic effect, VTA DA neuronal excitability is also profoundly modulated by intrinsic postsynaptic mechanisms, including the linkage of G-protein-coupled receptors to ion channels located on the cell membrane. $\mathrm{CB}_{2} \mathrm{Rs}$ are $\mathrm{G}$-protein-coupled receptors that, when activated, alter $\mathrm{G}$-protein $\left(\mathrm{G}_{\mathrm{i}} / \mathrm{G}_{\mathrm{o}}\right)$-coupled intracellular signaling cascades [49]. Emerging lines of evidence suggest that in VTA DA neurons, G-protein-coupled receptor signaling modulates neuronal excitability through several types of ion channels, e.g., G-protein-coupled inwardly rectifying $\mathrm{K}^{+}$channels (GIRK) [50-52], M-type $\mathrm{K}^{+}$channels [32,53,54], A-type of $\mathrm{K}^{+}$channels [55], and L-type voltage-gated $\mathrm{Ca}^{2+}$ channels [56]. In the present study, we found that JWH133 reduced neuron firing in acutely-dissociated VTA DA neurons by prolonging AP initiation, enhancing AHP amplitude and hyperpolarizing membrane potential, suggesting a potentiation of M-type $\mathrm{K}^{+}$current. Under voltage-clamp mode, we measured M-current in dissociated VTA DA neurons, and found a $\mathrm{CB}_{2} \mathrm{R}$-dependent enhancement of M-current amplitude by JWH133, confirming that $\mathrm{CB}_{2}$ Rs modulate M-current. M-channels are voltage-gated $\mathrm{K}^{+}$channels that strongly activate on depolarization to repolarize the cell, and potently regulate neuronal excitability $[57,58]$. Since M-type channels are activated at a membrane potential near the threshold for action potential initiation, it has a strong influence on neuronal excitability and responsiveness to synaptic inputs $[59,60]$, and plays a critical role in terminating bursting activity in hippocampal CA1 neurons [61]. Importantly, under resting physiological conditions, M-channels are not fully open. Single channel analysis of both native $[53,59]$ and recombinant $[62,63]$ Kv7.2/Kv7.3 channels demonstrates that the maximal channel open probability is $<1.0$, suggesting that there is a considerable range to fully activate M-channels, and therefore, regulate neuronal activity. It was reported that VTA DA neurons express M-type $\mathrm{K}^{+}$channels [32] and these channels play an important role in controlling VTA DA neuronal excitability [64]. It has been reported that activation of G-protein-coupled receptors increases M-currents in hippocampal neurons, by administration of somatostatin [65], corticostatin [66], or dynorphin [67]. This G-protein-mediated enhancement of M-current is important since it reduces neuronal excitability and counteracts convulsions. Indeed, it was also reported that the Mcurrent enhancer, retigabine, shifts the current-voltage curve to the left (so that the channels open at more hyperpolarized membrane potentials) and increases the maximal opening probability [68,69], therefore, producing a strong suppression of neuronal firing [68] and exhibiting a potent anticonvulsant effect [70]. We also compared the effects of JWH133 and retigabine on M-current and VTA DA neuronal firing. We found that JWH133 and retigabine enhanced M-current amplitude and reduced neuronal firing rate. However, in the presence of M-current blocker (XE991), JWH133 failed to inhibit VTA DA neuron firing. These results suggest that $\mathrm{CB}_{2} \mathrm{R}$-mediated enhancement of $\mathrm{M}$ current is an important intrinsic mechanism underlying the $\mathrm{CB}_{2} \mathrm{R}$ - 
mediated reduction in VTA DA neuronal excitability. Then, we further examined the signaling between $\mathrm{CB}_{2} \mathrm{R}$ activation and M-current enhancement. Based on the previous studies, activation of $\mathrm{CB}_{2} \mathrm{Rs}$ primarily initiates two signal pathways, MAPK/ERK and CAMP/PKA [37-39,48]. Considering cAMP plays an important role in modulation of M-current $[40]$ and neuronal firing $[71,72]$, we tested whether or not $C_{2} R$ induced reduction of cAMP contributes to the enhanced effect of Mcurrent. To reach this goal, we applied forskolin, a cAMP enhancer to the recorded cell to increase intracellular cAMP levels [73]. We tried to address 3 questions: [1] Does forskolin suppress M-current? [2] Does forskolin increase VTA DA neuron firing? [3] Does forskolin prevent JWH133-induced inhibition of VTA DA neuron firing? Our data clearly showed that forskolin $(10 \mu \mathrm{M})$ reduced $\mathrm{M}$-current and increased VTA DA neuron firing. In the presence of forskolin, JWH133 failed to potentiate $\mathrm{M}$-current and reduce AP firing. These results suggest that $\mathrm{CB}_{2} \mathrm{R}-\mathrm{G}$ protein-cAMP pathway likely plays a critical role in modulation of Mcurrent and consequently neuronal excitability. Thus, under our experimental conditions (in vitro preparations), the activation of somatodendritic $\mathrm{CB}_{2}$ Rs on VTA DA neurons reduces intracellular cAMP levels and enhances M-current amplitude, leading to a reduction in neuronal firing and excitability. However, in vivo conditions may be more complex, for example $\mathrm{CB}_{2} \mathrm{Rs}$ can modulate neuronal excitability by acting on glial cells $[74,75]$, by modulating endogenous cannabinoid substances or even by acting on peripheral cells.

Our findings that the $\mathrm{CB}_{2} \mathrm{R}$-mediated reduction of VTA DA neuronal excitability, the underlying intracellular signaling (cAMP) and target (M-channels) have translational significance. Accumulating lines of evidence demonstrate that $\mathrm{CB}_{2} \mathrm{Rs}$ mediate a variety of important modulations in DA-associated behaviors [76] including food intake, body weight [77-80], depression [81], anxiety [14,82], and schizophrenialike behavior $[15,83]$. Recent reports emerging from several labs, including ours, have shown brain $\mathrm{CB}_{2}$ Rs play a pivotal role in the elimination of cocaine, alcohol and nicotine addiction [84-86]. These lines of evidence strongly suggest an important impact of $\mathrm{CB}_{2} \mathrm{Rs}$ in the mesocorticolimbic system as well as critical roles in various brain functions including psychiatric, cognitive and neurobiological activity. The finding of the $\mathrm{CB}_{2} \mathrm{R}$-mediated reduction of midbrain DA neuronal excitability provides an insight into understanding of the roles played by $\mathrm{CB}_{2} \mathrm{Rs}$ in the above mentioned DA-associated function and diseases. When compared to $\mathrm{CB}_{1} \mathrm{Rs}$, brain $\mathrm{CB}_{2}$ Rs exhibit highly translational potential to be used in clinical practices since the following unique features: [1] Lower expression levels, suggesting that these receptors may not mediate the effect of cannabis under normal physiological conditions; [2] Highly inducible, meaning that under some pathological conditions (e.g., addiction, inflammation, stroke, schizophrenia, stress, anxiety, etc.), $\mathrm{CB}_{2} \mathrm{R}$ expression is enhanced in the brain [87], suggesting a close relationship between the alteration of $\mathrm{CB}_{2} \mathrm{R}$ expression/function and various psychiatric and neurological diseases; and [3] Exhibit special distribution, given that $\mathrm{CB}_{2} \mathrm{Rs}$ are chiefly expressed in neuronal somatodendritic areas [8] (postsynaptic) but $\mathrm{CB}_{1}$ Rs are predominantly expressed on neuronal terminals, especially on GABAergic terminals (presynaptic), which leads to some opposing effects after activation by these two receptor subtypes [88]. Considering these characteristic features, the mesolimbic $C_{2} R$ appears to be an important substrate for neuroprotection [89], and targeting $\mathrm{CB}_{2} \mathrm{Rs}$ or manipulations of their signaling (CAMP/PKA) and target (M-channels) will likely offer a novel therapeutic strategy for treating neuropsychiatric and neurological diseases without typical $\mathrm{CB}_{1} \mathrm{R}$-mediated sideeffects.

Supplementary data to this article can be found online at https://doi. org/10.1016/j.ebiom.2019.03.040.

\section{Conflicts of interest}

All authors have nothing to disclose.

\section{Author contributions}

Z.M., F.G., B.L., M.G., Z.L., D.C., X.M., S.Q., Y.Z., Z.X. conducted the experiments, analyzed data, prepared original figures, and revised the manuscript. Z.X. and J.X. participated in the experimental designs, analyzed the data, and revised the manuscript. J.W. designed and conducted the experiments, analyzed data, finalized figures, and wrote the manuscript.

\section{Acknowledgments}

This research was supported by the Barrow Neuroscience Foundation, the BNI-BMS Seed Fund, and CNSF (81771437). These funders have no role in study design, data collection, data analysis, interpretation, writing of the report.

\section{References}

[1] Galiegue S, Mary S, Marchand J, Dussossoy D, Carriere D, Carayon P, et al. Expression of central and peripheral cannabinoid receptors in human immune tissues and leukocyte subpopulations. Eur J Biochem 1995;232(1):54-61.

[2] Schatz AR, Lee M, Condie RB, Pulaski JT, Kaminski NE. Cannabinoid receptors CB1 and CB2: a characterization of expression and adenylate cyclase modulation within the immune system. Toxicol Appl Pharmacol 1997;142(2):278-87.

[3] McCoy KL, Matveyeva M, Carlisle SJ, Cabral GA. Cannabinoid inhibition of the processing of intact lysozyme by macrophages: evidence for $\mathrm{CB} 2$ receptor participation. J Pharmacol Exp Ther 1999;289(3):1620-5.

[4] Burdyga G, Lal S, Varro A, Dimaline R, Thompson DG, Dockray GJ. Expression of cannabinoid CB1 receptors by vagal afferent neurons is inhibited by cholecystokinin. J Neurosci 2004;24(11):2708-15.

[5] Munro S, Thomas KL, Abu-Shaar M. Molecular characterization of a peripheral receptor for cannabinoids. Nature 1993;365(6441):61-5.

[6] Buckley NE, McCoy KL, Mezey E, Bonner T, Zimmer A, Felder CC, et al. Immunomodulation by cannabinoids is absent in mice deficient for the cannabinoid CB(2) receptor. Eur J Pharmacol 2000;396(2-3):141-9.

[7] Buckley NE. The peripheral cannabinoid receptor knockout mice: an update. $\mathrm{Br} \mathrm{J}$ Pharmacol 2008;153(2):309-18.

[8] Onaivi ES, Ishiguro H, Gong JP, Patel S, Meozzi PA, Myers L, et al. Functional expression of brain neuronal CB2 cannabinoid receptors are involved in the effects of drugs of abuse and in depression. Ann N Y Acad Sci 2008;1139:434-49.

[9] Onaivi ES, Ishiguro H, Gong JP, Patel S, Perchuk A, Meozzi PA, et al. Discovery of the presence and functional expression of cannabinoid CB2 receptors in brain. Ann N Y Acad Sci 2006;1074:514-36.

[10] Skaper SD, Buriani A, Dal Toso R, Petrelli L, Romanello S, Facci L, et al. The ALIAmide palmitoylethanolamide and cannabinoids, but not anandamide, are protective in a delayed postglutamate paradigm of excitotoxic death in cerebellar granule neurons. Proc Natl Acad Sci U S A 1996;93(9):3984-9.

[11] Stempel AV, Stumpf A, Zhang HY, Ozdogan T, Pannasch U, Theis AK, et al. Cannabinoid type 2 receptors mediate a cell type-specific plasticity in the Hippocampus. Neuron 2016;90(4):795-809.

[12] Lanciego JL, Barroso-Chinea P, Rico AJ, Conte-Perales L, Callen L, Roda E, et al. Expression of the mRNA coding the cannabinoid receptor 2 in the pallidal complex of Macaca fascicularis. J Psychopharmacol 2011;25(1):97-104.

[13] Liu QR, Pan CH, Hishimoto A, Li CY, Xi ZX, Llorente-Berzal A, et al. Species differences in cannabinoid receptor 2 (CNR2 gene): identification of novel human and rodent CB2 isoforms, differential tissue expression and regulation by cannabinoid receptor ligands. Genes Brain Behav 2009;8(5):519-30.

[14] Garcia-Gutierrez MS, Garcia-Bueno B, Zoppi S, Leza JC, Manzanares J. Chronic blockade of cannabinoid $\mathrm{CB}(2)$ receptors induces anxiolytic-like actions associated to alterations in GABA(A) receptors. Br J Pharmacol 2012 Feb;165(4):951-64.

[15] Navarrete F, Perez-Ortiz JM, Manzanares J. Cannabinoid CB $(2)$ receptor-mediated regulation of impulsive-like behaviour in DBA/2 mice. Br J Pharmacol 2012;165 (1):260-73.

[16] Van Sickle MD, Duncan M, Kingsley PJ, Mouihate A, Urbani P, Mackie K, et al. Identification and functional characterization of brainstem cannabinoid CB2 receptors. Science 2005;310(5746):329-32.

[17] Viscomi MT, Oddi S, Latini L, Pasquariello N, Florenzano F, Bernardi G, et al. Selective $\mathrm{CB} 2$ receptor agonism protects central neurons from remote axotomy-induced apoptosis through the PI3K/Akt pathway. J Neurosci 2009;29(14):4564-70.

[18] Ashton JC, Friberg D, Darlington CL, Smith PF. Expression of the cannabinoid CB2 receptor in the rat cerebellum: an immunohistochemical study. Neurosci Lett 2006; 396(2):113-6.

[19] Baek JH, Zheng Y, Darlington CL, Smith PF. Cannabinoid CB2 receptor expression in the rat brainstem cochlear and vestibular nuclei. Acta Otolaryngol 2008;128(9): 961-7.

[20] Brusco A, Tagliaferro P, Saez T, Onaivi ES. Postsynaptic localization of CB2 cannabinoid receptors in the rat hippocampus. Synapse (New York NY) 2008;62(12):944-9.

[21] Gong JP, Onaivi ES, Ishiguro H, Liu QR, Tagliaferro PA, Brusco A, et al. Cannabinoid CB2 receptors: immunohistochemical localization in rat brain. Brain Res 2006; 1071(1):10-23. 
[22] Aracil-Fernandez A, Trigo JM, Garcia-Gutierrez MS, Ortega-Alvaro A, Ternianov A Navarro D, et al. Decreased cocaine motor sensitization and self-administration in mice overexpressing cannabinoid $\mathrm{CB}(2)$ receptors. Neuropsychopharmacology 2012;37(7):1749-63.

[23] Schmidt W, Schafer F, Striggow V, Frohlich K, Striggow F. Cannabinoid receptor subtypes 1 and 2 mediate long-lasting neuroprotection and improve motor behavior deficits after transient focal cerebral ischemia. Neuroscience 2012;227:313-26.

[24] Xi ZX, Peng XQ Li X, Song R, Zhang HY, Liu QR, et al. Brain cannabinoid CB receptors modulate cocaine's actions in mice. Nat Neurosci 2011;14(9):1160-6.

[25] Zhang HY, Gao M, Liu QR, Bi GH, Li X, Yang HJ, et al. Cannabinoid CB2 receptors modulate midbrain dopamine neuronal activity and dopamine-related behavior in mice. Proc Natl Acad Sci U S A 2014;111(46):E5007-15.

[26] Q-s Liu, Pu L, M-m Poo. Repeated cocaine exposure in vivo facilitates LTP induction in midbrain dopamine neurons. Nature 2005;437(7061):1027-31.

[27] Ungless MA, Whistler JL, Malenka RC, Bonci A. Single cocaine exposure in vivo induces long-term potentiation in dopamine neurons. Nature 2001;411(6837): $583-7$.

[28] Gao M, Jin Y, Yang K, Zhang D, Lukas RJ, Wu J. Mechanisms involved in systemic nicotine-induced glutamatergic synaptic plasticity on dopamine neurons in the ventral tegmental area. J Neurosci 2010;30(41):13814-25.

[29] Yang K, Buhlman L, Khan GM, Nichols RA, Jin G, McIntosh JM, et al. Functional nicotinic acetylcholine receptors containing alpha6 subunits are on GABAergic neuronal boutons adherent to ventral tegmental area dopamine neurons. J Neurosci 2011;31 (7):2537-48.

[30] Wu J, George AA, Schroeder KM, Xu L, Marxer-Miller S, Lucero L, et al. Electrophysiological, pharmacological, and molecular evidence for alpha7-nicotinic acetylcholine receptors in rat midbrain dopamine neurons. J Pharmacol Exp Ther 2004;311 (1):80-91.

[31] Yang K, Hu J, Lucero L, Liu Q, Zheng C, Zhen X, et al. Distinctive nicotinic acetylcholine receptor functional phenotypes of rat ventral tegmental area dopaminergic neurons. J Physiol 2009;587(Pt 2):345-61.

[32] Koyama S, Appel SB. Characterization of M-current in ventral tegmental area dopamine neurons. J Neurophysiol 2006;96(2):535-43.

[33] Brown DA, Passmore GM. Neural KCNQ (Kv7) channels. Br J Pharmacol 2009;156 (8):1185-95.

[34] Lee S, Kwag J. M-channels modulate the intrinsic excitability and synaptic responses of layer 2/3 pyramidal neurons in auditory cortex. Biochem Biophys Res Commun 2012;426(4):448-53.

[35] Schweitzer P. Cannabinoids decrease the $\mathrm{K}(+)$ M-current in hippocampal CA1 neurons. J Neurosci 2000;20(1):51-8.

[36] Brown DA, Adams PR. Muscarinic suppression of a novel voltage-sensitive K+ current in a vertebrate neurone. Nature 1980;283(5748):673-6.

[37] Childers SR, Deadwyler SA. Role of cyclic AMP in the actions of cannabinoid receptors. Biochem Pharmacol 1996;52(6):819-27.

[38] Pertwee RG. Pharmacology of cannabinoid CB1 and CB2 receptors. Pharmacol Ther 1997;74(2):129-80.

[39] Elphick MR, Egertova M. The neurobiology and evolution of cannabinoid signalling. Philos Trans R Soc Lond B Biol Sci 2001;356(1407):381-408.

[40] Stott JB, Povstyan OV, Carr G, Barrese V, Greenwood IA. G-protein betagamma subunits are positive regulators of Kv7.4 and native vascular Kv7 channel activity. Proc Natl Acad Sci U S A 2015;112(20):6497-502.

[41] Morgan NH, Stanford IM, Woodhall GL. Functional CB2 type cannabinoid receptors at CNS synapses. Neuropharmacology 2009;57(4):356-68.

[42] Atwood BK, Straiker A, Mackie K. CB(2) cannabinoid receptors inhibit synaptic transmission when expressed in cultured autaptic neurons. Neuropharmacology 2012;63 (4):514-23.

[43] Kim J, Li Y. Chronic activation of CB2 cannabinoid receptors in the hippocampus increases excitatory synaptic transmission. J Physiol 2015;593(4):871-86.

[44] Ashton JC, Glass M. The cannabinoid CB2 receptor as a target for inflammationdependent neurodegeneration. Curr Neuropharmacol 2007;5(2):73-80.

[45] Ben Achour S, Pascual O. Glia: the many ways to modulate synaptic plasticity. Neurochem Int 2010;57(4):440-5.

[46] Ellert-Miklaszewska A, Grajkowska W, Gabrusiewicz K, Kaminska B, Konarska L. Distinctive pattern of cannabinoid receptor type II (CB2) expression in adult and pediatric brain tumors. Brain Res 2007;1137(1):161-9.

[47] Zhang HY, Gao M, Shen H, Bi GH, Yang HJ, Liu QR, et al. Expression of functional cannabinoid CB receptor in VTA dopamine neurons in rats. Addict Biol 2017 May;22(3): 752-65.

[48] Pertwee RG. Pharmacological actions of cannabinoids. Handbook of Experimental Pharmacology, 168. ; 2005. p. 1-51

[49] Hille B. Modulation of ion-channel function by G-protein-coupled receptors. Trends Neurosci 1994;17(12):531-6

[50] Lomazzi M, Slesinger PA, Luscher C. Addictive drugs modulate GIRK-channel signaling by regulating RGS proteins. Trends Pharmacol Sci 2008;29(11):544-9.

[51] Hearing MC, Zink AN, Wickman K. Cocaine-induced adaptations in metabotropic inhibitory signaling in the mesocorticolimbic system. Rev Neurosci 2012;23(4): 325-51.

[52] Lalive AL, Munoz MB, Bellone C, Slesinger PA, Luscher C, Tan KR. Firing modes of dopamine neurons drive bidirectional GIRK channel plasticity. J Neurosci 2014;34(15): 5107-14.

[53] Appel SB, Liu Z, McElvain MA, Brodie MS. Ethanol excitation of dopaminergic ventral tegmental area neurons is blocked by quinidine. J Pharmacol Exp Ther 2003;306(2): 437-46.

[54] Hamasaki R, Shirasaki T, Soeda F, Takahama K. Tipepidine activates VTA dopamine neuron via inhibiting dopamine $\mathrm{D}(2)$ receptor-mediated inward rectifying $\mathrm{K}(+)$ current. Neuroscience 2013:252:24-34.
[55] Koyama S, Appel SB. A-type K+ current of dopamine and GABA neurons in the ventral tegmental area. J Neurophysiol 2006;96(2):544-54.

[56] Hoddah H, Marcantoni A, Comunanza V, Carabelli V, Carbone E. L-type channel inhibition by CB1 cannabinoid receptors is mediated by PTX-sensitive $G$ proteins and cAMP/PKA in GT1-7 hypothalamic neurons. Cell Calcium 2009;46(5-6):303-12.

[57] Brown DA, Higashida H. Voltage- and calcium-activated potassium currents in mouse neuroblastoma x rat glioma hybrid cells. J Physiol 1988;397:149-65.

[58] Jentsch TJ. Neuronal KCNQ potassium channels: physiology and role in disease. Nat Rev Neurosci 2000;1(1):21-30.

[59] Marrion NV. Control of M-current. Annu Rev Physiol 1997;59:483-504.

60] Aiken SP, Lampe BJ, Murphy PA, Brown BS. Reduction of spike frequency adaptation and blockade of M-current in rat CA1 pyramidal neurones by linopirdine (DuP 996), a neurotransmitter release enhancer. Br J Pharmacol 1995;115(7):1163-8.

[61] Azouz R, Jensen MS, Yaari Y. Ionic basis of spike after-depolarization and burst generation in adult rat hippocampal CA1 pyramidal cells. J Physiol 1996;492:211-23 Pt 1.

[62] Selyanko AA, Hadley JK, Brown DA. Properties of single M-type KCNQ2/KCNQ3 potassium channels expressed in mammalian cells. J Physiol 2001;534:15-24 Pt 1.

[63] Li Y, Gamper N, Shapiro MS. Single-channel analysis of KCNQ K+ channels reveals the mechanism of augmentation by a cysteine-modifying reagent. J Neurosci 2004;24(22):5079-90.

[64] Drion G, Bonjean M, Waroux O, Scuvee-Moreau J, Liegeois JF, Sejnowski TJ, et al. Mtype channels selectively control bursting in rat dopaminergic neurons. Eur J Neurosci 2010;31(5):827-35.

[65] Moore SD, Madamba SG, Joels M, Siggins GR. Somatostatin augments the M-current in hippocampal neurons. Science 1988;239(4837):278-80.

[66] de Lecea L, Criado JR, Prospero-Garcia O, Gautvik KM, Schweitzer P, Danielson PE et al. A cortical neuropeptide with neuronal depressant and sleep-modulating properties. Nature 1996;381(6579):242-5.

[67] Madamba SG, Schweitzer P, Siggins GR. Dynorphin selectively augments the Mcurrent in hippocampal CA1 neurons by an opiate receptor mechanism. J Neurophysiol 1999;82(4):1768-75.

[68] Tatulian L, Delmas P, Abogadie FC, Brown DA. Activation of expressed KCNQ potassium currents and native neuronal M-type potassium currents by the anticonvulsant drug retigabine. J Neurosci 2001;21(15):5535-45.

[69] Tatulian L, Brown DA. Effect of the KCNQ potassium channel opener retigabine on single KCNQ2/3 channels expressed in CHO cells. J Physiol 2003;549:57-63 Pt 1.

[70] Arora D, Hearing M, Haluk DM, Mirkovic K, Fajardo-Serrano A, Wessendorf MW et al. Acute cocaine exposure weakens GABA(B) receptor-dependent G-proteingated inwardly rectifying $\mathrm{K}+$ signaling in dopamine neurons of the ventral tegmental area. J Neurosci 2011;31(34):12251-7.

[71] Gruart A, Benito E, Delgado-Garcia JM, Barco A. Enhanced cAMP response elementbinding protein activity increases neuronal excitability, hippocampal long-term potentiation, and classical eyeblink conditioning in alert behaving mice. J Neurosci 2012;32(48):17431-41

[72] Jancic D, Lopez de Armentia M, Valor LM, Olivares R, Barco A. Inhibition of cAMP response element-binding protein reduces neuronal excitability and plasticity, and triggers neurodegeneration. Cereb Cortex 2009;19(11):2535-47.

[73] Alasbahi RH, Melzig MF. Forskolin and derivatives as tools for studying the role of cAMP. Pharmazie 2012;67(1):5-13.

[74] Guida F, Luongo L, Boccella S, Giordano ME, Romano R, Bellini G, et al Palmitoylethanolamide induces microglia changes associated with increased migration and phagocytic activity: involvement of the CB2 receptor. Sci Rep 2017;7(1): 375.

[75] Luchicchi A, Lecca S, Carta S, Pillolla G, Muntoni AL, Yasar S, et al. Effects of fatty acid amide hydrolase inhibition on neuronal responses to nicotine, cocaine and morphine in the nucleus accumbens shell and ventral tegmental area: involvement of PPAR-alpha nuclear receptors. Addict Biol 2010;15(3):277-88.

[76] Vlachou S, Panagis G. Regulation of brain reward by the Endocannabinoid system: a critical review of Behavioral studies in animals. Curr Pharm Des 2014;20(13) 2072-88.

[77] Agudo J, Martin M, Roca C, Molas M, Bura AS, Zimmer A, et al. Deficiency of CB2 cannabinoid receptor in mice improves insulin sensitivity but increases food intake and obesity with age. Diabetologia 2010;53(12):2629-40.

[78] Ignatowska-Jankowska B, Jankowski MM, Swiergiel AH. Cannabidiol decreases body weight gain in rats: involvement of CB2 receptors. Neurosci Lett 2011;490(1):82-4

[79] Emadi L, Jonaidi H, Hosseini Amir Abad E. The role of central CB2 cannabinoid receptors on food intake in neonatal chicks. J Comp Physiol A Neuroethol Sens Neural Behav Physiol 2011;197(12):1143-7.

[80] Flake NM, Zweifel LS. Behavioral effects of pulp exposure in mice lacking cannabinoid receptor 2. J Endod 2012;38(1):86-90.

[81] Garcia-Gutierrez MS, Perez-Ortiz JM, Gutierrez-Adan A, Manzanares J. Depressionresistant endophenotype in mice overexpressing cannabinoid $\mathrm{CB}(2)$ receptors. $\mathrm{Br} J$ Pharmacol 2010;160(7):1773-84.

[82] Garcia-Gutierrez MS, Manzanares J. Overexpression of CB2 cannabinoid receptors decreased vulnerability to anxiety and impaired anxiolytic action of alprazolam in mice. J Psychopharmacol 2011;25(1):111-20.

[83] Ortega-Alvaro A, Aracil-Fernandez A, Garcia-Gutierrez MS, Navarrete F, Manzanares J. Deletion of CB2 cannabinoid receptor induces schizophrenia-related behaviors in mice. Neuropsychopharmacology 2011;36(7):1489-504.

[84] Xi ZX, Peng XQ Li X, Song R, Zhang HY, Liu QR, et al. Brain cannabinoid CB(2) receptors modulate cocaine's actions in mice. Nat Neurosci 2011:14(9):1160-6.

[85] Navarrete F, Rodriguez-Arias M, Martin-Garcia E, Navarro D, Garcia-Gutierrez MS, Aguilar MA, et al. Role of CB2 cannabinoid receptors in the rewarding, reinforcing, and physical effects of nicotine. Neuropsychopharmacology 2013 Nov;38(12): 2515-24. 
[86] Ortega-Alvaro A, Ternianov A, Aracil-Fernandez A, Navarrete F, Garcia-Gutierrez MS, Manzanares J. Role of cannabinoid $\mathrm{CB}$ receptor in the reinforcing actions of ethanol. Addict Biol 2015 Jan;20(1):43-55.

[87] Miller LK, Devi LA. The highs and lows of cannabinoid receptor expression in disease: mechanisms and their therapeutic implications. Pharmacol Rev 2011;63(3): 461-70.
[88] Onaivi ES, Ishiguro H, Gu S, Liu QR. CNS effects of CB2 cannabinoid receptors: beyond neuro-immuno-cannabinoid activity. J Psychopharmacol 2012;26(1):92-103.

[89] Pacher P, Mechoulam R. Is lipid signaling through cannabinoid 2 receptors part of a protective system? Prog Lipid Res 2011;50(2):193-211. 